Document downloaded from:

http://hdl.handle.net/10251/148464

This paper must be cited as:

Scarazzato, T.; Panossian, Z.; García Gabaldón, M.; Ortega Navarro, EM.; Tenório, J.; Pérez-Herranz, V.; Espinosa, D. (2017). Evaluation of the transport properties of copper ions through a heterogeneous ion-exchange membrane in etidronic acid solutions by chronopotentiometry. Journal of Membrane Science. 535:268-278.

https://doi.org/10.1016/j.memsci.2017.04.048

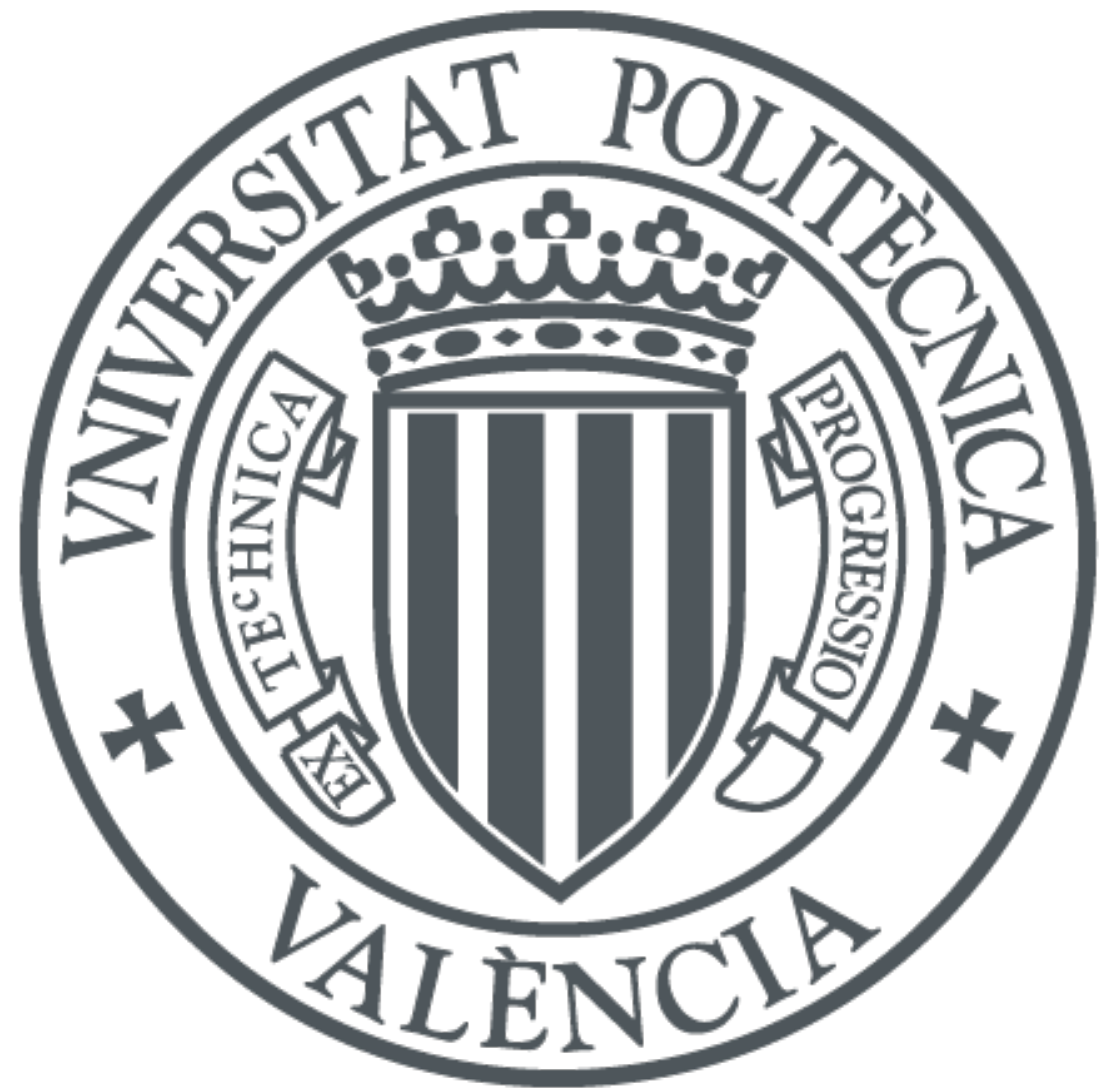

The final publication is available at

https://doi.org/10.1016/j.memsci.2017.04.048

Copyright Elsevier

Additional Information 


\title{
Evaluation of the transport properties of copper ions through a heterogeneous ion-exchange membrane in etidronic acid solutions by chronopotentiometry
}

\author{
T. Scarazzato *a. V. Pérez-Herranz ${ }^{\text {b. }}$; M. García-Gabaldón ${ }^{\text {b. E. Ertega }}{ }^{\text {b }}$; Z. Panossian \\ c; J.A.S. Tenório ${ }^{\text {a; }}$ D.C.R. Espinosa ${ }^{a}$ \\ ${ }^{a}$ Chemical Engineering Department, Universidade de São Paulo, Av. Prof. Lineu Prestes \\ 580, Bloco 18, 05434-070, São Paulo, SP, Brazil. \\ ${ }^{b}$ IEC Group, Departament d'Enginyeria Quimica i Nuclear, Universitat Politècnica de \\ València, Camí de Vera s/n, 46022, València, P.O. Box 22012, E-46071, Spain. \\ ${ }^{c}$ Institute for Technological Research, Corrosion and Protection Laboratory, Av. Prof. \\ Almeida Prado, 532, 05508-901, São Paulo, SP, Brazil and invited professor of \\ Department of Metallurgical and Material Engineering, Universidade de São Paulo, Av. \\ Prof. Mello Moraes, 2463, 05508-030, São Paulo, SP, Brazil.
}

\begin{abstract}
The transport properties of copper chelates across an anion-exchange membrane were investigated by means of chronopotentiometry. Several solutions containing etidronic acid, copper sulfate and potassium chloride were evaluated. Tests were accomplished in a three-compartment reactor using a heterogeneous membrane containing quaternary ammonium functional groups. Results showed a strong relation between the amount of chelated anions and the limiting current density, the electrical resistance and the concentration polarization. An increase in the anionic equivalent charge of the solutions modified the three regions of the current-voltage curves. The acid medium was found to be less favorable because of the possibility of the formation of non-charged species in overlimiting regions. The presence of chloride anions increased the limiting current density, especially when the chloride concentration exceeded the etidronic acid concentration.
\end{abstract}

Keywords: copper chelates; etidronic acid; anion-exchange membrane; chronopotentiometry; current-voltage curve.

\section{INTRODUCTION}

The transport of ions across ion-exchange membranes has been widely studied since it can involve complex interactions between counter ions and fixed functional groups for a given current density regime. Throughout the last years, many researches have been developed in order to describe ion transport properties in several electrodialysis applications. Special attention has been given to the effects of membrane heterogeneity, to mass transfer enhancement in overlimiting regimes, to the influence of 
different electrolytes in the transport of transition metals and to the effect of complex formation in the transfer properties [1-11].

The study of ion transport through semipermeable membranes is often performed with the aid of chronopotentiometry, a classical electrochemical characterization method that measures the potential difference of a system in response of an imposed current density $[12,13]$. One of the most important advantages of chronopotentiometry for membrane systems is the possibility of measuring the dynamic potential drop response as a function of time which can provide more detailed information on non-steady transport state in the membrane and in the adjacent solution layers. Some of the suitable boundary conditions assumed are the existence of an interface between an ion-selective surface and an electrolyte solution and an ion transport controlled by semi-infinite diffusion and governed by the second Fick's law. In the established conditions, the chronopotentiometric curves present a characteristic shape exhibited in several studies [12-14].

A typical chronopotentiometric arrangement for studying membrane systems consists in a four-electrode assemblage in which one reference electrode is positioned near each of the membrane-electrolyte interfaces. The potential response between the reference electrodes is registered while a current density is applied between the working electrode and the counter electrode. The shape of the chronopotentiometric curves provides information regarding to the parameters related to ion transport across the membrane, i.e., the limiting current density, the electrical resistance, the effect of overlimiting transport mechanisms and the transport number of an ion $[15,16]$.

In the present work, chronopotentiometry was used to investigate the transport properties of copper chelates across an anion exchange membrane. The evaluated chelating agent was 1-hydroxyethane-1,1-diphosphonic acid (HEDP or etidronic acid). The etidronic acid is an organophosphonate used as chelating agent mostly for industrial cleaning applications. It is produced from the reaction between phosphorus trichloride $\left(\mathrm{PCl}_{3}\right)$ and acetic acid $\left(\mathrm{CH}_{3} \mathrm{COOH}\right)$, resulting in a bisphosphonate having its molecular structure as presented in Figure 1 [17].<smiles>CC(O)(P(=O)(O)O)P(=O)(O)O</smiles>

Figure 1. Structural formulae of etidronic acid (HEDP) [17].

Etidronic acid has been evaluated as a less toxic alternative for cyanide in plating baths [18-20]. A HEDP-based alkaline strike bath for copper plating on Zamak 
substrates in barrel plating systems was developed by the Institute for Technological Research, in Brazil [19]. As a result, a suitable bath was produced and the electrodeposited copper coats exhibited adherence and visual aspect comparable with cyanide-based baths. It is important to mention that the main characteristic of a strike bath is its ability to form stable metal complexes and decrease the $\mathrm{Me}^{\mathrm{z+}}$ reduction potential. Strike baths are utilized to perform metal deposition as undercoats to prevent the lack of adherence caused by galvanic deposition. According to the literature $[19,21,22]$, the most probable cupric [CuHEDP] chelates to be formed are $[\mathrm{CuHEDP}]^{2-}$, [CuHHEDP] $]^{-}$and $\left[\mathrm{CuH}_{2} \mathrm{HEDP}\right]$. In alkaline solutions $(\mathrm{pH}>7)$, [CuHEDP] $]^{2-}$ is the prevailing found specie [21].

Another study [23] evaluated electrodialysis (ED) as an alternative for treating synthetic wastewaters from the mentioned HEDP-copper bath. Authors obtained percent extraction up to $99.7 \%$ of copper ions and $94.4 \%$ of HEDP, indicating that electrodialysis may be an alternative for treating HEDP-based solutions. The study also showed that, for synthetic wastewaters with $\mathrm{pH}$ higher than 5.4, copper ions were transferred to the anodic side of the ED system, in accordance with the anionic chelate formation theory. Nevertheless, no clogging in anionic membranes was observed [23].

Due to the formation of stable anionic cupric chelates observed previously, the present work proposes a detailed investigation on the transport properties of [CuHEDP] chelates through an anion exchange membrane using chronopotentiometry. The effect of the HEDP: $\mathrm{Cu}^{2+}$ ratio was evaluated by using several solutions having ion concentration similar to the synthetic rinsing waters from the strike copper bath. The influence of $\mathrm{pH}$ and of potassium chloride addition was also investigated.

\section{EXPERIMENTAL}

\subsection{Working solutions}

The study was carried out using solutions containing copper (II) sulfate pentahydrate $\left(\mathrm{CuSO}_{4} .5 \mathrm{H}_{2} \mathrm{O}\right)$, etidronic acid (HEDP) and potassium chloride $(\mathrm{KCl})$ in different concentrations. Analytical grade reagents and deionized water were employed. The $\mathrm{pH}$ of all solutions was adjusted with a $\mathrm{KOH} 50 \% \mathrm{w} / \mathrm{w}$ solution. The composition of the solutions is shown in Table 1. The objective for the selection of the solution composition is also presented in Table 1. 
Table 1. Composition of the working solutions.

\begin{tabular}{llll}
\hline Objective & Composition $\left(\mathbf{x} 10^{-3} \mathbf{~ m o l}^{-1}\right)$ & $\mathrm{pH}$ & $\mathrm{ID}$ \\
\hline Effect of chelation & $5.1(\mathrm{HEDP})+0.71\left(\mathrm{Cu}^{2+}\right)$ & 10 & $\mathrm{I}$ \\
& $2.8(\mathrm{HEDP})+0.71\left(\mathrm{Cu}^{2+}\right)$ & 10 & $\mathrm{II}$ \\
& $0.71(\mathrm{HEDP})+0.71\left(\mathrm{Cu}^{2+}\right)$ & 10 & $\mathrm{III}$ \\
& $0.71(\mathrm{HEDP})+0.18\left(\mathrm{Cu}^{2+}\right)$ & 10 & $\mathrm{IV}$ \\
& $0.71(\mathrm{HEDP})+0.10\left(\mathrm{Cu}^{2+}\right)$ & 10 & $\mathrm{~V}$ \\
\hline Effect of $\mathrm{pH}$ & $5.1(\mathrm{HEDP})$ & 2 & $\mathrm{VI}$ \\
& $5.1(\mathrm{HEDP})$ & 10 & $\mathrm{VII}$ \\
\hline Effect of $\mathrm{Cl}^{-}$addition & $0.71(\mathrm{HEDP})+0.10\left(\mathrm{Cu}^{2+}\right)+0.94\left(\mathrm{Cl}^{-}\right)$ & 10 & $\mathrm{VIII}$ \\
& $5.1(\mathrm{HEDP})+0.71\left(\mathrm{Cu}^{2+}\right)+0.94\left(\mathrm{Cl}^{-}\right)$ & 10 & $\mathrm{IX}$ \\
& $5.1(\mathrm{HEDP})+0.71\left(\mathrm{Cu}^{2+}\right)+5.1\left(\mathrm{Cl}^{-}\right)$ & 10 & $\mathrm{X}$ \\
& $5.1(\mathrm{HEDP})+0.71\left(\mathrm{Cu}^{2+}\right)+10.2\left(\mathrm{Cl}^{-}\right)$ & 10 & $\mathrm{XI}$ \\
\hline
\end{tabular}

\section{2 lon exchange membrane}

The membrane under investigation is a heterogeneous anionic membrane (HDX200) which contains quaternary amine groups $\left(\mathrm{NR}_{3}{ }^{+}\right)$and its structure has double reinforcing fabrics. Table 2 presents the main properties of the membrane.

Table 2. Characteristics of the HDX200 membrane [23]

\begin{tabular}{lcc}
\hline Parameter & Unit & HDX200 \\
\hline Membrane matrix & - & polymeric \\
lonic group attached & - & $\mathrm{NR}_{3}{ }^{+}$ \\
Water content & $\%$ & $30-45$ \\
lon exchange capacity $(\mathrm{NaCl})$ & $\mathrm{mol} . \mathrm{kg}^{-1}(\mathrm{dry})$ & $\geq 1.8$ \\
Membrane surface resistance $(0.1 \mathrm{~mol} \mathrm{NaCl})$ & $\Omega . \mathrm{cm}^{-2}$ & $\leq 20$ \\
Permselectivity $(0.1 \mathrm{~mol} \mathrm{KCl} / 0.2 \mathrm{~mol} \mathrm{KCl})$ & $\%$ & $\geq 89$ \\
Burst strength & $\mathrm{MPa}$ & $\geq 0.6$ \\
Dimension change rate & $\%$ & $\leq 2.0$ \\
Water permeability & $\mathrm{mL} \cdot \mathrm{h}^{-1} \cdot \mathrm{cm}^{-2}$ & $\leq 0.2(<0.035 \mathrm{MPa})$ \\
\hline
\end{tabular}

\subsection{Electrochemical reactor}

Tests were performed using a three-compartment reactor. Each compartment was filled with $140 \mathrm{~mL}$ of working solutions. The studied membrane was positioned between the anodic compartment and the central compartment. The effective membrane area was $3.52 \mathrm{~cm}^{2}$. An auxiliary cationic membrane was positioned between the cathodic compartment and the central compartment in order to avoid the transport of hydroxyl ions from the cathode redox reactions. Graphite electrodes were used at the extremities 
of the system and connected to a galvanostat/potentiostat as working and counter electrodes. Two Ag/AgCl reference electrodes immersed in Luggin capillaries were used to measure the potential differences through the anionic membrane. A schematic representation of the reactor is presented in Figure 2.

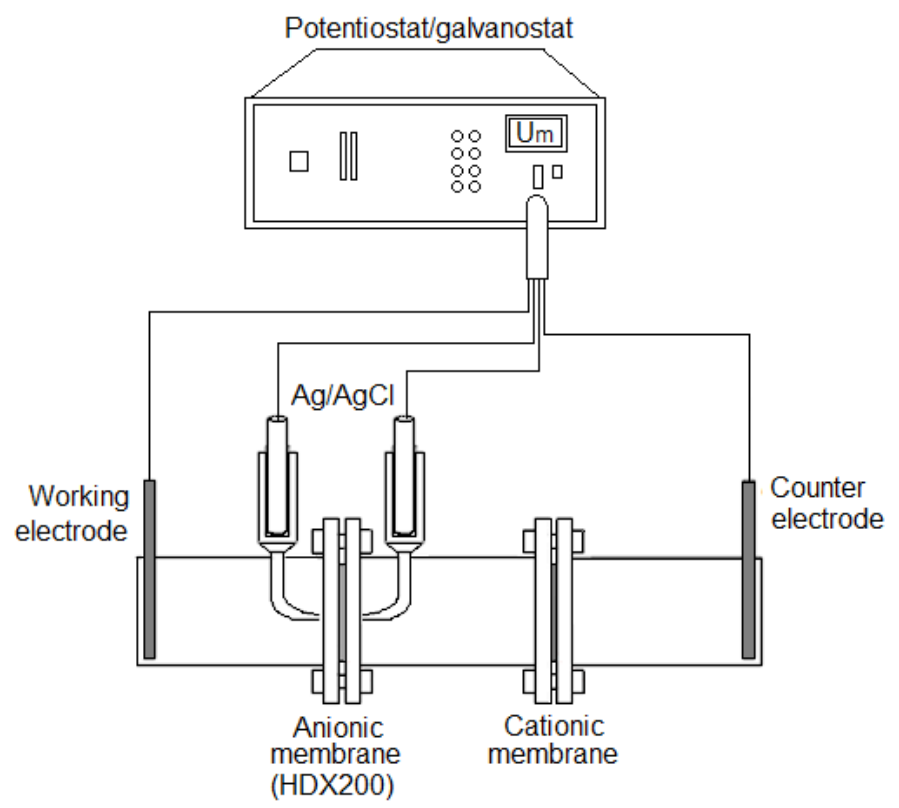

Figure 2. Schematic representation of the experimental setup.

\subsection{Chronopotentiometric tests}

Before the beginning of each experiment, the membranes were immersed in the working solutions under stirring for at least $24 \mathrm{~h}$. In all tests, the three compartments were filled with the same working solution. Tests were performed in duplicate, at room temperature and with no stirring. During the chronopotentiometric tests, different current densities were applied between the working and counter electrodes for $300 \mathrm{~s}$, while the membrane potential difference $(\mathrm{Um})$ between the two reference electrodes was registered. After $300 \mathrm{~s}$, the current was interrupted and the membrane potential was measured for an additional $100 \mathrm{~s}$. The chronopotentiometric curves and the current voltage curves were constructed by plotting the registered steady values of Um against the time or the applied current density, respectively.

\section{RESULTS AND DISCUSSION}

\subsection{Effect of the formation of anionic chelates}

The transport properties of HEDP anions and copper-HEDP chelates through the HDX200 anion exchange membrane (AEM) were evaluated by means of chronopotentiometric curves. Synthetic solutions containing HEDP and $\mathrm{CuSO}_{4} \cdot 5 \mathrm{H}_{2} \mathrm{O}$ 
with different HEDP: $\mathrm{Cu}^{2+}$ ratios were used. The compositions of the working solutions that were used for the evaluation of the chelation effect are detailed in Table 3.

Table 3. Composition of the working solutions used for the evaluation of the chelation effect.

\begin{tabular}{ccccc}
\hline ID & HEDP $\left(\mathbf{m m o l . L ^ { - 1 } )}\right.$ & $\mathbf{C u}^{2+}\left(\mathbf{m m o l . L ^ { - 1 }}\right)$ & HEDP: $\mathbf{C u}^{2+}$ & $\mathbf{p H}^{*}$ \\
\hline I & 5.1 & 0.71 & $7: 1$ & 10 \\
II & 2.8 & 0.71 & $4: 1$ & 10 \\
III & 0.71 & 0.71 & $1: 1$ & 10 \\
IV & 0.71 & 0.18 & $4: 1$ & 10 \\
V & 0.71 & 0.10 & $7: 1$ & 10 \\
\hline
\end{tabular}

${ }^{*}$ adjusted with $50 \% \mathrm{w} / \mathrm{w} \mathrm{KOH}$

The chronopotentiometric curves obtained for the working solutions for a current density of $0.28 \mathrm{~mA} . \mathrm{cm}^{-2}$ are presented in Figure 3.

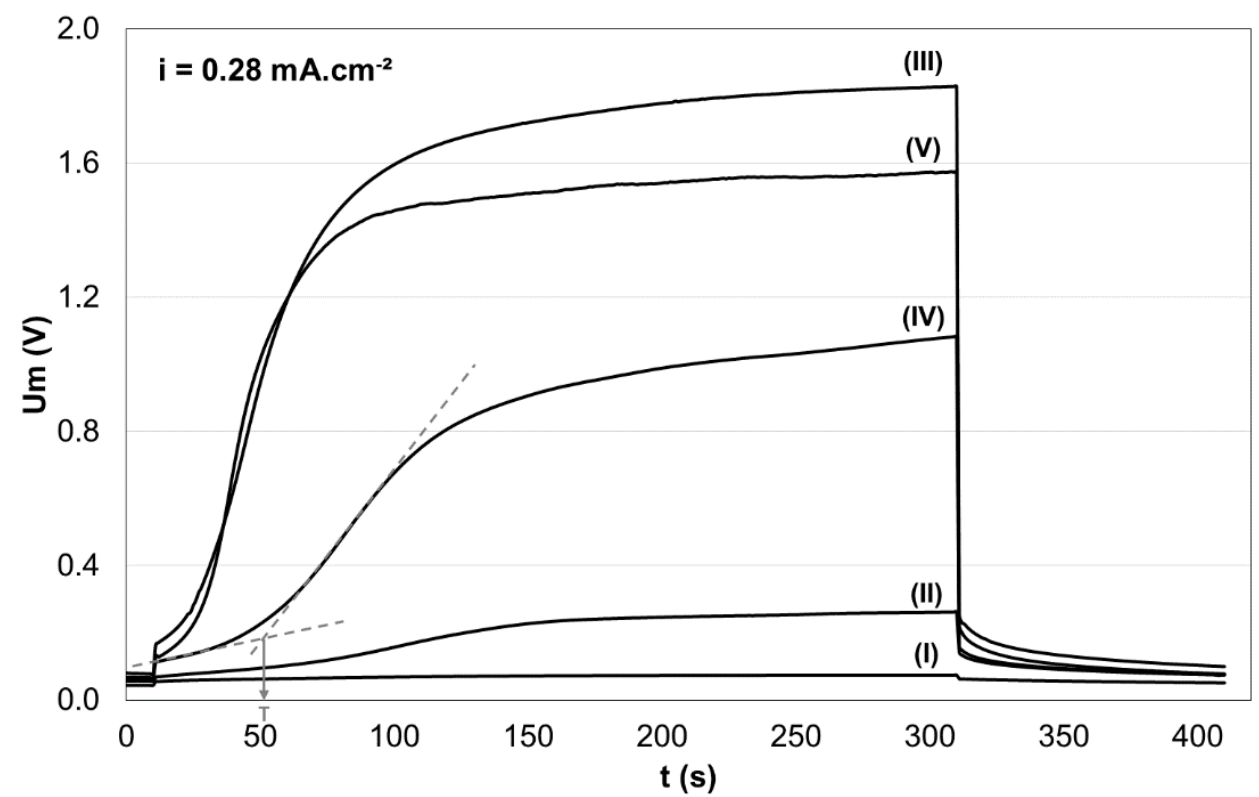

Figure 3. Chronopotentiometric curves for HDX200 membrane in contact with different solutions for $0.28 \mathrm{~mA} . \mathrm{cm}^{-2}$.

In Figure 3, the curves showed different shapes, although the same current density was applied in all systems. The curve from solution I did not show any inflexion point which indicates that the ion transport is not limited by a diffusion mechanism. The registered potential difference is related only to the ohmic drop and to the membrane resistance. Curve II presented a slight increase in the membrane potential between 100 $\mathrm{s}$ and $150 \mathrm{~s}$. This indicates the onset of a slight concentration gradient.

An inflexion point was well defined in curves III, IV and $\mathbf{V}$ showing anion depletion in the diffusion boundary layer. In these situations, the ion transport was limited by the 
diffusion of ions from the bulk of the solution towards the boundary layer. The elapsed time until the appearance of the inflexion point is known as transition time (T).

From the chronopotentiometric curves, the precipitation of insoluble copper hydroxides was not observed because an increase of the membrane potential after the steady-state was not detected. It has been related in the literature $[16,24]$ that metal-hydroxide precipitation can modify the shape of chronopotentiometric curves during the ion transport through cation exchange membranes. The formation of metal hydroxides is a consequence of water splitting in the membrane boundary layer or the rapid transport of protons through the cationic membranes. These two phenomena lead the increase of hydroxyl group and consequently the increases of the $\mathrm{pH}$ at one side of the membrane leading to the formation of insoluble metal hydroxides which can clog the membrane surface. Similar behavior is possible to occur with anion exchange membranes [25]. Under overlimiting current conditions, the metal hydroxide precipitation is characterized by an increase of the membrane potential after the steady-state is reached. The region of the curve attributed to the relaxation of the system can be altered due to the recombination between the formed hydroxides and the protons in the solution [3]. However, the described effects were not observed in the present studied systems.

The chronopotentiometric curves obtained for solutions with different HEDP: $\mathrm{Cu}^{2+}$ ratios indicated that there is a relation between the HEDP concentration, the fraction of [CuHEDP] chelates and the shape of the curves. The curve from solution III (HEDP:Cu ${ }^{2+}$ $=1$ ) presented the greatest ohmic drop immediately after the current application and the highest potential drop registered for the overlimiting regime. The beginning of concentration polarization was noted for a current density of $0.14 \mathrm{~mA} . \mathrm{cm}^{-2}$, the lowest value among all the studied systems. This behavior is possibly attributed to the fact that solution III has no free HEDP in its composition. Practically, the total amount of HEDP in solution III is in the form of [CuHEDP] chelates which may have lower mobility and bigger size than the other anions.

The results presented in Figure 3 show that, under the same current density, different transport mechanisms were acting in each system. This may be explained considering the different molar concentration and the ionic mobility of all species under a given condition. The formation of organometallic chelates with HEDP has been intensively studied in the last few years $[17,21,26-28]$. The HEDP dissociation follows the reactions (1)-(4) [21].

$$
\begin{array}{lr}
\mathrm{H}^{+}+\mathrm{HEDP}^{4-} \leftrightarrow \mathrm{HHEDP}^{3-} & \log \mathrm{K}=11.0 \\
2 \mathrm{H}^{+}+\mathrm{HEDP}^{4-} \leftrightarrow \mathrm{H}_{2} \mathrm{HEDP}^{2-} & \log \mathrm{K}=17.9 \\
3 \mathrm{H}^{+}+\mathrm{HEDP}^{4-} \leftrightarrow \mathrm{H}_{3} \mathrm{HEDP}^{-} & \log \mathrm{K}=20.6
\end{array}
$$


$4 \mathrm{H}^{+}+\mathrm{HEDP}^{4-} \leftrightarrow \mathrm{H}_{4} \mathrm{HEDP} \quad \log \mathrm{K}=22.2$

The reactions of anionic HEDP chelates with copper are: (5)-(7) [21].

$$
\begin{aligned}
& \mathrm{Cu}^{2+}+\mathrm{HEDP}^{4-} \leftrightarrow[\text { CuHEDP }]^{2-} \quad \log \mathrm{K}=12.0 \\
& \mathrm{H}^{+}+\mathrm{Cu}^{2+}+\mathrm{HEDP}^{4-} \leftrightarrow[\text { CuHHEDP] } \quad \log \mathrm{K}=17.4 \\
& 2 \mathrm{H}^{+}+\mathrm{Cu}^{2+}+\mathrm{HEDP}^{4-} \leftrightarrow\left[\mathrm{CuH}_{2} \mathrm{HEDP}\right] \quad \log \mathrm{K}=20.4
\end{aligned}
$$

In aqueous solutions, insoluble copper hydroxides and soluble compounds may be formed as shown by the reactions (8)-(14).

$$
\begin{array}{ll}
\mathrm{Cu}^{2+}+2 \mathrm{H}_{2} \mathrm{O} \leftrightarrow 2 \mathrm{H}^{+}+\mathrm{Cu}(\mathrm{OH})_{2} & \log \mathrm{K}=-16.24 \\
\mathrm{Cu}^{2+}+3 \mathrm{H}_{2} \mathrm{O} \leftrightarrow 3 \mathrm{H}^{+}+\mathrm{Cu}(\mathrm{OH})_{3}^{-} & \log \mathrm{K}=-26.7 \\
\mathrm{Cu}^{2+}+4 \mathrm{H}_{2} \mathrm{O} \leftrightarrow 4 \mathrm{H}^{+}+\mathrm{Cu}(\mathrm{OH})_{4}^{2-} & \log \mathrm{K}=-39.6 \\
2 \mathrm{Cu}^{2+}+2 \mathrm{H}_{2} \mathrm{O} \leftrightarrow 2 \mathrm{H}^{+}+\mathrm{Cu}_{2}(\mathrm{OH})_{2}{ }^{2+} & \log \mathrm{K}=-10.35 \\
2 \mathrm{Cu}^{2+}+\mathrm{H}_{2} \mathrm{O} \leftrightarrow \mathrm{H}^{+}+\mathrm{Cu}_{2} \mathrm{OH}^{3+} & \log \mathrm{K}=-6.7 \\
3 \mathrm{Cu}^{2+}+4 \mathrm{H}_{2} \mathrm{O} \leftrightarrow 4 \mathrm{H}^{+}+\mathrm{Cu}_{3}(\mathrm{OH})_{4}{ }^{2+} & \log \mathrm{K}=-21.1 \\
\mathrm{Cu}^{2+}+\mathrm{H}_{2} \mathrm{O} \leftrightarrow \mathrm{H}^{+}+\mathrm{CuOH}^{+} & \log \mathrm{K}=-7.96 \\
\mathrm{Cu}^{2+}+2 \mathrm{H}_{2} \mathrm{O} \leftrightarrow 2 \mathrm{H}^{+}+\mathrm{Cu}(\mathrm{OH})_{2(\mathrm{~s})} & \log \mathrm{K}=-8.64 \\
\mathrm{Cu}^{2+}+\mathrm{H}_{2} \mathrm{O} \leftrightarrow 2 \mathrm{H}^{+}+\mathrm{CuO}(\mathrm{s}) & \log \mathrm{K}=-7.68
\end{array}
$$

The formation of other sulfate and potassium compounds was taken into account with reactions (17)-(20). Potassium hydroxide ( $\mathrm{KOH} 50 \% \mathrm{w} / \mathrm{w})$ was added for $\mathrm{pH}$ adjustment. Sulfate anions are available because of the dissociation of $\mathrm{CuSO}_{4} \cdot 5 \mathrm{H}_{2} \mathrm{O}$.

$$
\begin{array}{ll}
\mathrm{CuSO}_{4} .5 \mathrm{H}_{2} \mathrm{O} \leftrightarrow \mathrm{Cu}^{2+}+\mathrm{SO}_{4}{ }^{2-}+5 \mathrm{H}_{2} \mathrm{O} & \log \mathrm{K}=2.31 \\
\mathrm{KOH} \leftrightarrow \mathrm{K}^{+}+\mathrm{OH}^{-} & \log \mathrm{K}=-14.46 \\
\mathrm{KSO}_{4}^{-} \leftrightarrow \mathrm{K}^{+}+\mathrm{SO}_{4}{ }^{2-} & \log \mathrm{K}=-0.85 \\
\mathrm{HSO}_{4}^{-} \leftrightarrow \mathrm{H}^{+}+\mathrm{SO}_{4}{ }^{2-} & \log \mathrm{K}=-1.98
\end{array}
$$

The stability constants of reactions (5)-(20) were obtained from the database of the Hydra-Medusa $®$ software. The same program was used to calculate the molar concentration of all ionic species in the systems containing HEDP and divalent copper ions and to build equilibrium diagrams for each system. The calculated molar concentration of the main ionic species for each solution is presented in Table 4. 
Table 4. Molar concentration (in mmol. $\mathrm{L}^{-1}$ ) of ionic species for the [CuHEDP] evaluated systems.

\begin{tabular}{|c|c|c|c|c|c|}
\hline Solution & $\mathbf{I}$ & II & III & IV & $\mathbf{V}$ \\
\hline \multicolumn{6}{|c|}{ Composition of the working solutions } \\
\hline HEDP $\left(m m o l . L^{-1}\right)$ & 5.10 & 2.80 & 0.71 & 0.71 & 0.71 \\
\hline $\mathrm{Cu}^{2+}\left(\mathrm{mmol} . \mathrm{L}^{-1}\right)$ & 0.71 & 0.71 & 0.71 & 0.18 & 0.10 \\
\hline $\mathrm{K}^{+}\left(\mathrm{mmol} . \mathrm{L}^{-1}\right)$ & 32.0 & 13.0 & 8.0 & 5.4 & 5.4 \\
\hline $\mathrm{pH}$ & 10.3 & 10.0 & 9.9 & 10.7 & 10.4 \\
\hline \multicolumn{6}{|c|}{ Concentration (in mmol. $\mathrm{L}^{-1}$ ) of the main ionic species } \\
\hline $\mathrm{K}^{+}$ & 31.84 & 13.03 & 7.83 & 5.30 & 5.40 \\
\hline Hhedp ${ }^{3-}$ & 3.63 & 1.95 & 0.01 & 0.37 & 0.49 \\
\hline [CuHEDP] $^{2-}$ & 0.71 & 0.69 & 0.71 & 0.18 & 0.10 \\
\hline $\mathrm{OH}^{-}$ & 0.20 & 0.09 & 0.07 & 0.46 & 0.28 \\
\hline $\mathrm{SO}_{4}{ }^{2-}$ & 0.58 & 0.64 & 0.67 & 0.17 & 0.10 \\
\hline hedp ${ }^{4-}$ & 0.74 & 0.17 & $8.91 \times 10^{-4}$ & 0.17 & 0.13 \\
\hline $\mathrm{KSO}_{4}^{-}$ & 0.13 & 0.06 & 0.04 & 0.01 & $3.67 \times 10^{-3}$ \\
\hline $\mathrm{Cu}^{2+}$ & $8.87 \times 10^{-10}$ & $4.12 \times 10^{-9}$ & $8.13 \times 10^{-7}$ & $9.98 \times 10^{-10}$ & $7.43 \times 10^{-10}$ \\
\hline \multicolumn{6}{|l|}{ Equivalent charge } \\
\hline $\mathbf{Q}_{\text {eq }}^{-}$ & 16.78 & 9.35 & 2.91 & 2.95 & 2.67 \\
\hline
\end{tabular}

The formation of insoluble compounds was not considered in the equilibrium diagrams since there was no indication of copper precipitation neither visually nor in the chronopotentiometric curves. The equivalent charge $\left(Q_{e q}\right)$ for the cationic and the anionic species were calculated using the Equation (21):

$Q_{e q}=\sum\left|z_{j}\right| \cdot C_{j}$

In Equation $21, z_{j}$ is the charge and $C_{j}$ is the concentration of a given ion $j . \ln$ Table 4 , it is noted that the prevailing anions were: $\mathrm{HHEDP}^{3-}, \mathrm{SO}_{4}{ }^{2-}, \mathrm{OH}^{-}, \mathrm{HEDP}^{4-}$, $\mathrm{KSO}_{4}{ }^{-}$and $[\mathrm{CuHEDP}]^{2-}$ chelates. Therefore, a transport competition between them was expected, depending on their molar concentration and mobility. Solution I presented the highest HEDP concentration and the HEDP: $\mathrm{Cu}^{2+}$ ratio was equal to 7 . The predominant anion in this solution was the HHEDP ${ }^{3-}$ and its molar concentration was about 5 times greater than $\mathrm{HEDP}^{4-}$ and [CuHEDP] ${ }^{2-}$ anions. In this case, it is possible to suggest that the ion transport through the membrane is mainly accomplished by $\mathrm{HHEDP}^{3-}$ anions.

In solution III, the HEDP: $\mathrm{Cu}^{2+}$ ratio was equal to 1 and practically the total amount of HEDP formed bivalent anionic chelates with copper in the evaluated $\mathrm{pH}$ range. The transfer of electric charges in the membrane phase occurs due to the transport of [CuHEDP] ${ }^{2-}$ chelates and $\mathrm{SO}_{4}{ }^{2-}$ anions. Both have similar equivalent charges but the 
anionic chelates have lower mobility. The effect of the $[\mathrm{CuHEDP}]^{2-}$ transport was noticeable in the chronopotentiometric curves shown in Figure 3.

The prevalence of $\mathrm{HHEDP}^{3-}$ anions was smaller in the remaining solutions (II, IV and $\mathbf{V}$ ). The simultaneous transport of other anionic species became more pronounced and the transport properties were not governed by HHEDP ${ }^{3-}$. Solutions IV and $\mathbf{V}$ have lower acid molar concentration in their composition and presented interference by $\mathrm{OH}^{-}$ anions. The hydroxyl groups may have contributed for reducing the ohmic drop and the membrane potential, as presented in Figure 3.

The transfer of anions with different mobility was noted under specific conditions in the chronopotentiometric curves obtained for solutions having HEDP: $\mathrm{Cu}^{2+}$ ratio equal to 4 (Figure 4).

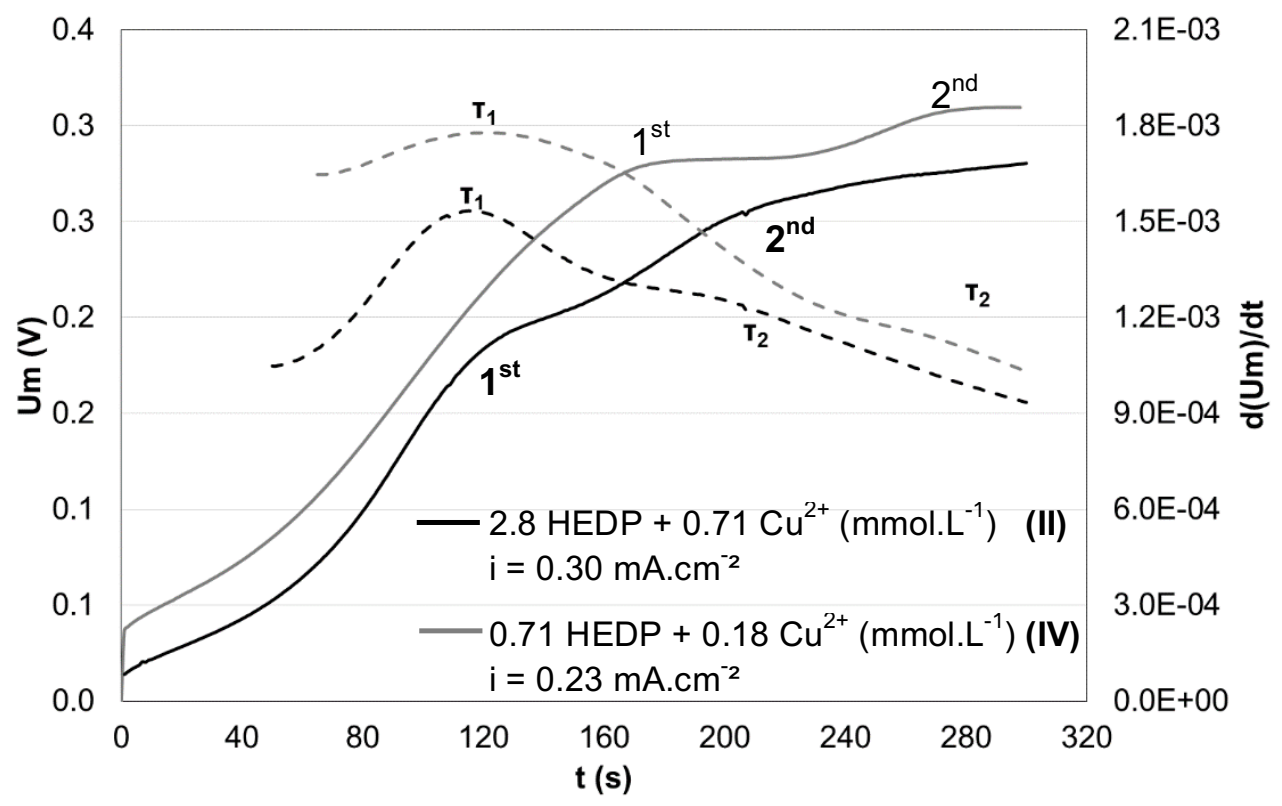

Figure 4. Chronopotentiometric curves obtained for solutions having HEDP:Cu ${ }^{2+}$ ratio equal to 4 . Dashed lines show the transition times $(\mathrm{T})$ calculated according to the maximum of the first derivative method.

The curves shown in Figure 4 presented two inflexion points, instead of a single inflexion point generally observed in similar systems. This behavior may be attributed to the transport of anions with different size, molar concentrations, mobility or diffusion coefficients in the membrane matrix. A similar characteristic was observed by Zook et al. [29]. The authors studied the ion transport through a $\mathrm{Ca}^{2+}$ selective membrane in contact with a solution containing an ionophore and calcium cations. According to the authors, the first inflexion point was assigned to the transport of free ionophore, the second inflexion point was attributed to ion-ionophore complex transfer and both inflexion points were clearly separated from each other, indicating a difference in ion mobility and diffusion coefficient [29]. Pismenskaya et al. [30] reported that $\mathrm{pH}$ changes on a membrane surface due to the preferential transport of hydroxyl ions may also modify the 
transport properties of weak electrolyte anions, depending on the membrane selectivity for each charged species.

Each inflexion point presented in Figure 4 was associated with a transition time. Transition times were calculated using the maximum of the first derivative method $[1,13]$. The existence of a second inflexion point was more noticeable for solution II because of its higher ion concentration. Based on the equilibrium diagrams of the working solutions in their initial conditions, it is possible to suggest that the first inflexion point observed in Figure 4 may be associated with the transport of $\mathrm{HHEDP}^{3-}$ free anions and the second inflexion point may be related to $[\mathrm{CuHEDP}]^{2-}$ chelate transfer through the membrane. Figure 5 presents the equilibrium diagram of solution II $\left(\mathrm{HEDP}: \mathrm{Cu}^{2+}=4\right)$, considering its initial conditions.
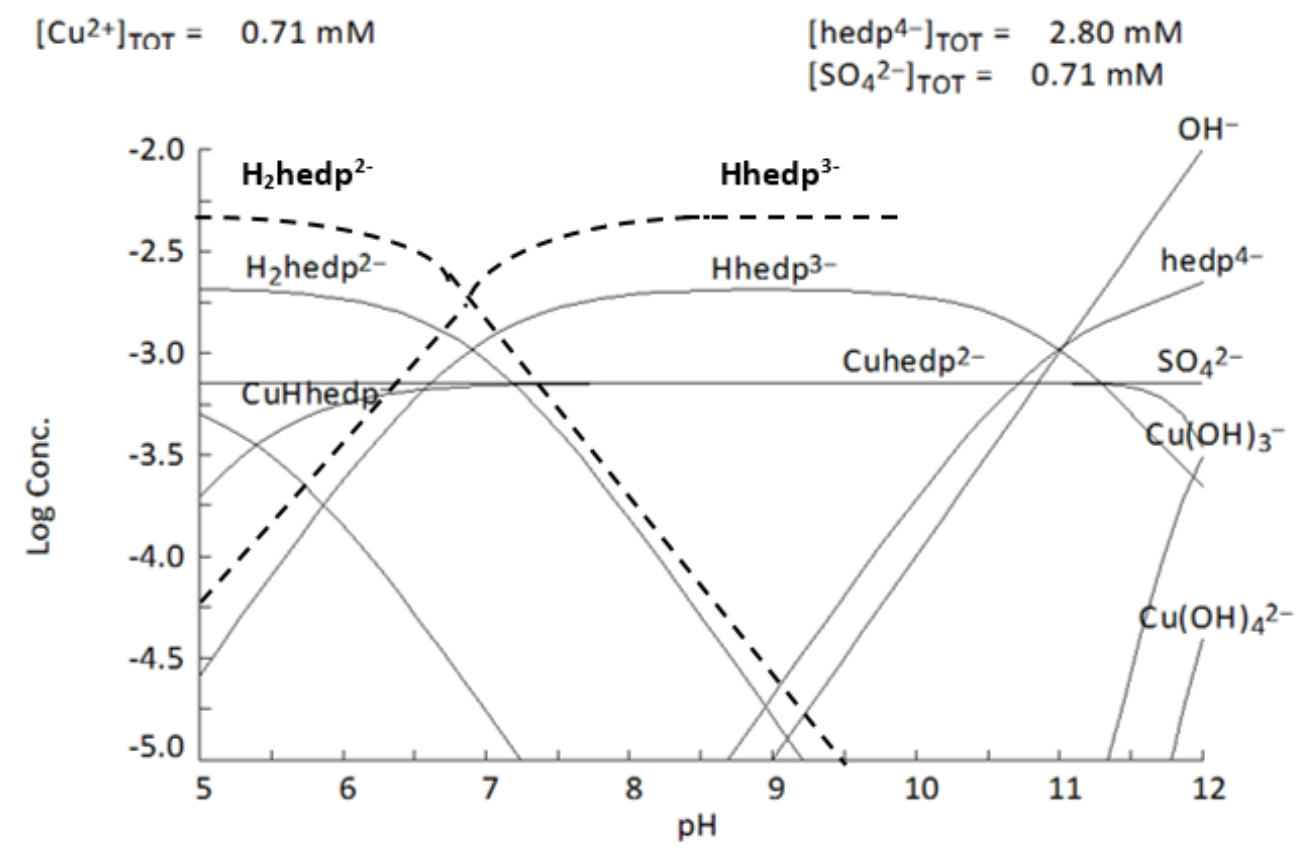

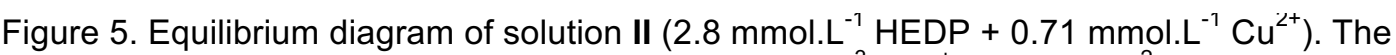
dashed lines represent the chemical reaction HHEDP ${ }^{3-}+\mathrm{H}^{+} \leftrightarrow \mathrm{H}_{2} \mathrm{HEDP}^{2-}$ for solution I $\left(5.1 \mathrm{mmol} . \mathrm{L}^{-1} \mathrm{HEDP}+0.71 \mathrm{mmol} \cdot \mathrm{L}^{-1} \mathrm{Cu}^{2+}\right)$. The equilibrium diagram was constructed with the aid of Hydra-Medusa software.

From Figure 5, the initial composition of solution II for $\mathrm{pH} 10$ shows a HHEDP $^{3-}:[\mathrm{CuHEDP}]^{2-}$ ratio equal to 2.8 . When the overlimiting regime is reached, a depletion of $\mathrm{HHEDP}^{3-}$ anions occurs at the boundary layer, as they are transported towards the anode compartment. The anion depletion may lead to the appearance of overlimiting transfer mechanisms, such as electroconvection and water splitting. The hydroxyl groups from water splitting mechanism or from the autoionization of water in alkaline medium are transferred to the anode compartment and cause a $\mathrm{pH}$ raise at the anodic side of the AEM. On the other hand, $\mathrm{H}^{+}$protons, which are excluded from the 
AEM matrix due to Donnan's exclusion mechanism, provoke a decrease in the $\mathrm{pH}$ value at the cathodic side of the AEM. The decrease in $\mathrm{pH}$ value favors the formation of $\mathrm{H}_{2} \mathrm{HEDP}^{2-}$ anions according to the following reaction (22):

$\mathrm{HHEDP}^{3-}+\mathrm{H}^{+} \leftrightarrow \mathrm{H}_{2} \mathrm{HEDP}^{2-}$

The formation of $\mathrm{H}_{2} \mathrm{HEDP}^{2-}$ reduces the $\mathrm{HHEDP}^{3-}$ :[CuHEDP] ${ }^{2-}$ ratio, as it can be seen in Figure 5. [CUHEDP] ${ }^{2-}$ chelates present a greater size and a lower mobility than the other anions. Thus, their transport across the AEM membrane is characterized by a second transition time in the chronopotentiometric curves. By comparing the results with the chronopotentiometric curves obtained for solution I, it is observed that, when the HHEDP $^{3-}:[\text { CuHEDP }]^{2-}$ ratio is higher (represented by the dotted lines in Figure 5 ), the [CuHEDP ${ }^{2-}$ ] chelate transport becomes less evident and the appearance of the second inflexion point is suppressed.

Other transport properties of ions can be evaluated by means of the construction of current voltage curves. The limiting current density, the electrical resistance of the system and the plateau length provide some additional information regarding the ion transfer through the membrane. The current-voltage curves obtained for the solutions listed in Table 3 are presented in Figure 6.

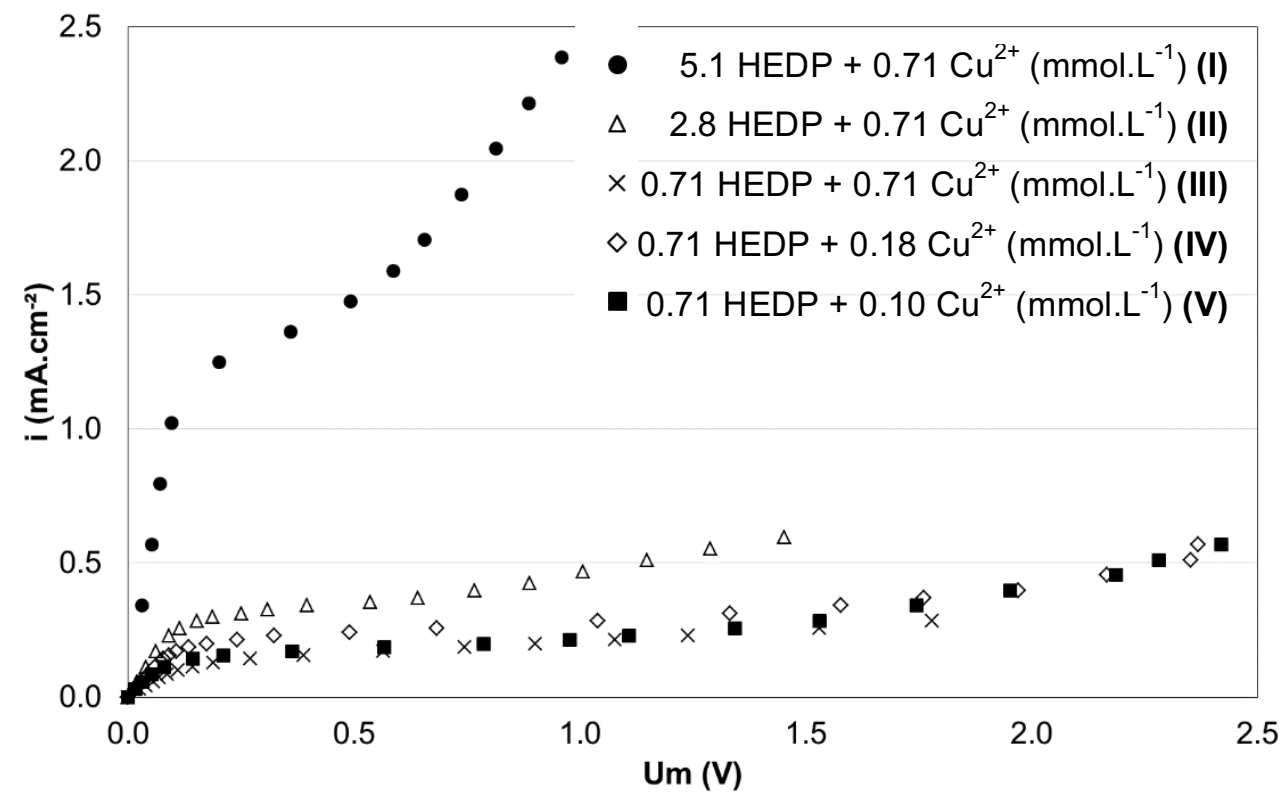

Figure 6. Current-voltage curves obtained for HDX200 membrane and solutions containing HEDP and $\mathrm{Cu}^{2+}$.

Current voltage curves shown in Figure 6 present three characteristic regions. The first region, known as the ohmic region, presents a linear dependence between the membrane potential and the current density. The ion transport inside the membrane 
matrix occurs mainly due to migration under the electrical potential as a driving force. Ion diffusion from the bulk solution to the membrane boundary layer transfers the counterions towards the anodic compartment. The system's electrical resistance is represented by the inverse of the slope of the ohmic region.

The second region is characterized by a plateau where small current increments cause high potential raises due to ion depletion in the boundary layer. This behavior is observed because the transport is limited by the ion diffusion from the bulk solution to the boundary layer for high current densities. The plateau length is related to the energy required to overcome the diffusion layer and favor the overlimiting transport mechanisms, such as electroconvection and water splitting. The interception between the tangents of the first and the second regions determines the limiting current density of the system. This current density is defined as the maximum current density that can be applied to the system to ensure that concentration polarization is avoided.

In the third region, the membrane potential shows a new linear dependence with the applied current density. The overlimiting mechanisms starts enhancing the mass transfer, either by the contribution of the water splitting or by the convective flow on the membrane surface [31]. The electrical resistance at the third region can be determined similarly to the ohmic region, i.e., by the inverse of the slope assigned to the overlimiting region.

In Figure 6, it is observed that the increase in the HEDP:Cu${ }^{2+}$ ratio by means of HEDP addition (solutions I and II) promoted some alterations in the current-voltage curves. The limiting current density was raised and the electrical resistance in the ohmic region was reduced. Since the molar concentration of $\mathrm{SO}_{4}{ }^{2-}$ and $\mathrm{Cu}^{2+}$ was kept constant in all solutions, it is possible to suggest that the changes in the transport properties occurred as a consequence of the higher amount of HHEDP ${ }^{3-}$ anion.

Solution III presented the lowest limiting current density and the highest electrical resistance in the ohmic region of all evaluated systems. The HEDP: $\mathrm{Cu}^{2+}$ ratio in solution III is equal to 1 , which means that almost the total amount of HEDP formed anionic chelates $\left([\mathrm{CuHEDP}]^{2-}\right.$ ) for the evaluated $\mathrm{pH}$ range, as described by Equation 5 . The slowest mobility of chelates and their greater molecular volume are likely the reasons for the observed changes in the current-voltage curve characteristics.

In Solutions IV and $\mathbf{V}$, the HEDP: $\mathrm{Cu}^{2+}$ ratio was modified by decreasing the chelate molar concentration. The HEDP concentration was fixed on $0.71 \mathrm{mmol} . \mathrm{L}^{-1}$ in both solutions. The current-voltage curves obtained for solutions IV and $\mathbf{V}$ seemed to be less affected by the amount of free HEDP than solution I. This result may be explained by the transport competition between different anions. As presented in Table 4, the molar 
concentration of all anionic species of Solutions IV and $\mathbf{V}$ is more uniform and does not show a predominant value, as observed for solution $\mathbf{I}$.

The equivalent charge may be used to represent the main parameters related to ion transport through ion-exchange membranes, especially when multicomponent electrolyte solutions are employed [5,31]. The relation between the anionic equivalent charge, the limiting current density $\left(i_{\text {lim }}\right)$ and the electrical resistance in ohmic region $\left(R_{1}\right)$ for all evaluated solutions are presented in Figure 7.

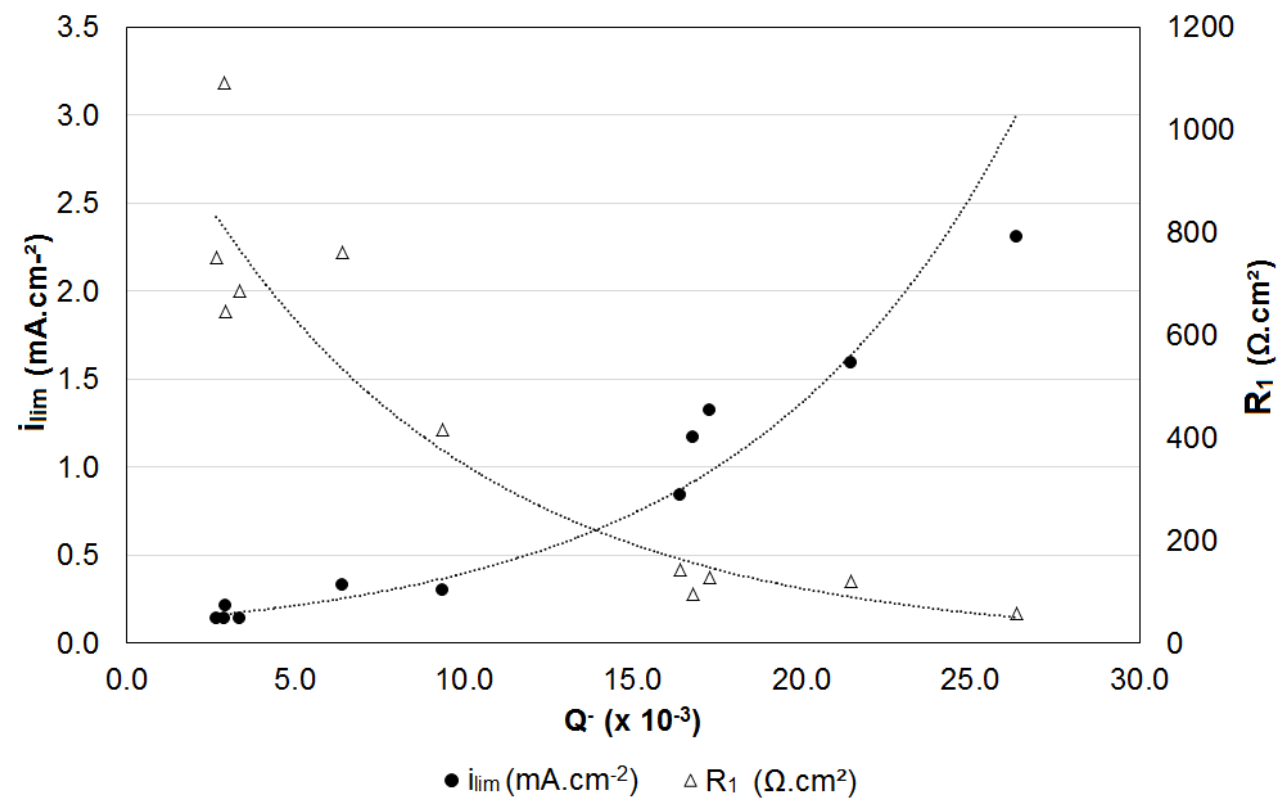

Figure 7. Limiting current density $\left(i_{\text {lim }}\right)$ and electrical resistance $\left(R_{1}\right)$ in ohmic region as a function of anionic equivalent charge $\left(Q^{-}\right)$for the evaluated solutions.

It is observed from Figure 7 that the limiting current density increased when the anionic equivalent charge was enhanced. On the contrary, the higher equivalent charges seemed to reduce the electrical resistance in the ohmic region. The prevailing species in solutions with higher equivalent charges is the HHEDP ${ }^{3-}$. Some of these solutions were also influenced by $\mathrm{Cl}^{-}$anions which were added in different concentrations. The effect of the chloride addition will be discussed in more detail in section 3.3. The higher amount of available negative charges for electrical current conduction was probably the reason for the increase in the limiting current density. The higher concentration and, consequently, the higher equivalent charge also caused an increase in the electrical conductivity which can explain the reduction of the electrical resistance $\left(R_{1}\right)$. Similar relations between the equivalent charge and the electrical resistance were reported by other authors [5,31-33].

Figure 8 presents the obtained electrical conductivity of the overlimiting region $\left(\Lambda_{3}\right)$ and the plateau length as a function of the anionic equivalent charge for each solution. 


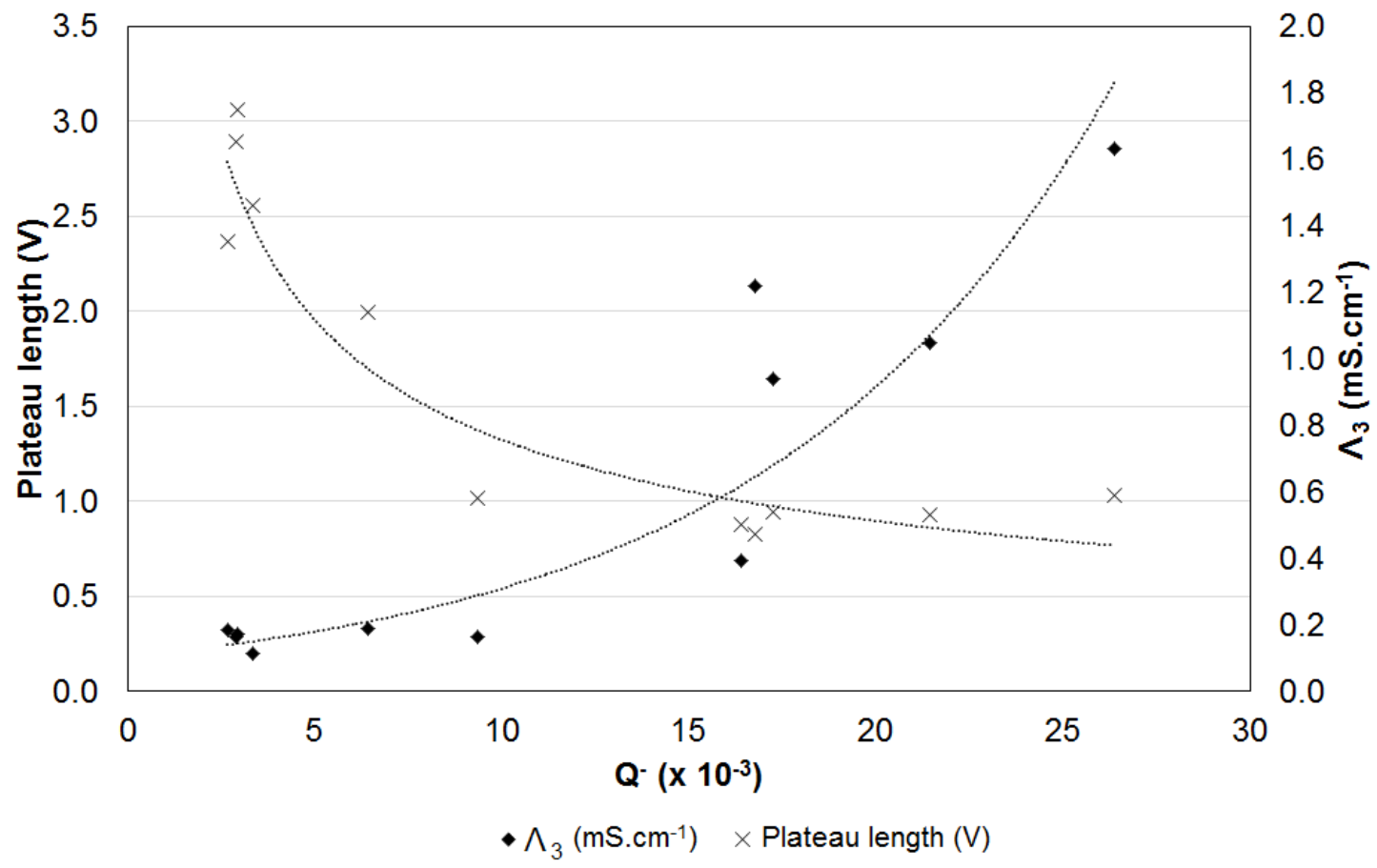

Figure 8. Plateau length and electrical conductivity of the overlimiting region $(\wedge 3)$ as a function of the anionic equivalent charge (Q-) obtained for each solution.

As observed from Figure 8, the plateau length decreased with the increase of the anionic equivalent charge, especially when $Q^{-}$is lower than $10 \times 10^{-3}$. This relation was reported previously [5,34] for cationic ion-exchange membranes. According to the authors [5,34], the plateau length is related to the change of the ion transfer mechanism, from diffusion to an overlimiting mechanism, such as water splitting or electroconvection. Therefore, it is possible to suggest that the overlimiting mechanism is activated for lower membrane potential for solutions with higher equivalent charges. As described by Belova et al. [35], heterogeneous anion exchange membranes with quaternary ammonium fixed charges may favor electroconvection for overlimiting regimes.

When the plateau length is smaller (solutions with higher equivalent charges), the electroconvection mechanism is initiated earlier. The total equivalent charge and the equivalent charge for each anion of all solutions are presented in Table 5. It is observed that the equivalent charge of $\mathrm{HHEDP}^{3-}$ ions are predominant in solutions with higher equivalent charges. Therefore, $\mathrm{HHEDP}^{3-}$ anions are the main species that activate electroconvection for solutions I, II, VII, IX, X and XI.

Table 5. Predominant anionic equivalent charges of the solutions under investigation.

\begin{tabular}{|c|c|c|c|c|c|c|c|c|c|c|}
\hline \multirow{2}{*}{$\begin{array}{c}\text { Plateau } \\
\text { (V) }\end{array}$} & \multirow{2}{*}{ ID } & \multicolumn{9}{|c|}{ Q- $\left(\times 10^{-3}\right)$} \\
\hline & & Total & HHEDP $^{3-}$ & CuHEDP $^{2-}$ & $\mathrm{Cl}^{-}$ & $\mathrm{SO}_{4}{ }^{2-}$ & HEDP $^{4-}$ & $\mathrm{H}_{2} \mathrm{HEDP}^{2-}$ & $\mathrm{H}_{3} \mathrm{HEDP}^{-}$ & $\mathrm{OH}^{-}$ \\
\hline 1.75 & IV & 2.95 & 1.12 & 0.35 & - & 0.34 & 0.68 & - & - & 0.46 \\
\hline
\end{tabular}




\begin{tabular}{ccccccccccc}
\hline 1.65 & III & 2.91 & - & 1.42 & - & 1.34 & - & - & - & - \\
1.46 & VIII & 3.34 & 1.71 & 0.20 & 0.96 & 0.19 & 0.19 & - & - & - \\
1.35 & V & 2.67 & 1.46 & 0.20 & - & 0.19 & 0.54 & - & - & 0.28 \\
1.14 & VI & 6.41 & - & - & - & - & - & 3.47 & 2.94 & - \\
0.59 & $\mathrm{XI}$ & 26.37 & 11.97 & 1.42 & 10.12 & 1.12 & 1.49 & - & - & - \\
0.58 & $\mathrm{II}$ & 9.35 & 5.86 & 1.38 & - & 1.27 & - & - & - & - \\
0.54 & $\mathrm{IX}$ & 17.27 & 11.67 & 1.43 & 0.94 & 1.18 & 1.82 & - & - & - \\
0.53 & $\mathrm{X}$ & 21.46 & 11.51 & 1.41 & 5.04 & 1.14 & 2.08 & - & - & - \\
0.50 & $\mathrm{VII}$ & 16.41 & 13.80 & - & - & - & 2.44 & - & - & 0.13 \\
0.47 & $\mathrm{I}$ & 16.78 & 10.89 & 1.42 & - & 1.16 & 2.97 & - & - & - \\
\hline
\end{tabular}

In Figure 8, the region that presents a sharp decline of the plateau length is related to solutions III, IV, V, VI and VIII which present an equivalent charge about 10 times smaller than the other solutions. By analyzing solutions III, IV, V and VIII in Table 5 , it is observed that the greatest contribution of the equivalent charge of HHEDP ${ }^{3-}$ and $[\mathrm{CuHEDP}]^{2-}$ anions causes a shorter plateau length. This indicates that even for the solutions with smaller equivalent charges, HHEDP ${ }^{3-}$ and $[\text { CuHEDP] }]^{2-}$ favor the overlimiting transfer mechanisms.

The obtained results may be interpreted considering that the plateau length is reduced when the Péclet number increases [36]. The Péclet number is usually proportional to the Stokes radius of a given ion. The relation between the Stokes radius and the plateau length of a current-voltage curve $\left(U_{m}\right.$ versus $\left.i\right)$ was observed for the ion transport through cation exchange membranes $[5,34,36]$ and it seemed to be suitable for the results shown in Figure 8. According to this theory, ions with larger Stokes radius can activate electroconvection earlier and can reduce the electrical potential for which the changes of the transfer mechanism occur. Martí-Calatayud et al. [5] studied the transport of nickel through a cation exchange membrane and observed that, in acid solutions, the increase of nickel concentration favored the beginning of electroconvection, since $\mathrm{Ni}^{2+}$ cations have greater Stokes radius than $\mathrm{H}^{+}$.

In Table 5, solutions $\mathbf{I}$ and $\mathbf{X I}$ can be compared, since they had the same composition (5.1 mmol.L ${ }^{-1} \mathrm{HEDP}+0.71 \mathrm{mmol} . \mathrm{L}^{-1} \mathrm{Cu}^{2+}$ ), except that $10.2 \mathrm{mmol} . \mathrm{L}^{-1} \mathrm{KCl}$ were added to solution $\mathbf{X I}$. It can be seen that the plateau length increased from $0.47 \mathrm{~V}$ (solution I) to $0.59 \mathrm{~V}$ (solution $\mathbf{X I}$ ) after $\mathrm{Cl}^{-}$addition. Similarly, solution $\mathbf{V}$ had the same composition as solution VIII $\left(0.71 \mathrm{mmol} . \mathrm{L}^{-1} \mathrm{HEDP}+0.10 \mathrm{mmol} . \mathrm{L}^{-1} \mathrm{Cu}^{2+}\right)$ and $0.94 \mathrm{mmol} . \mathrm{L}^{-1} \mathrm{KCl}$ were added to solution VIII. The plateau length was enhanced from $1.35 \mathrm{~V}$ to $1.46 \mathrm{~V}$. This behavior suggests that the $\mathrm{Cl}^{-}$addition delayed the beginning of electroconvection. Considering that the Péclet number is proportional to the atomic 
radius [36], a smaller Péclet number for $\mathrm{Cl}^{-}$ions than for $\mathrm{HHEDP}^{3-}$ anions may be expected.

Figure 8 also shows the influence of equivalent charge in the electrical conductivity for overlimiting regimes $\left(\Lambda_{3}\right)$. According to Choi et al. [36], the same theory that considers the Péclet number can be applied to evaluate the electrical conductivity. Ions having larger Stokes radius can favor the intensity of electroconvection which causes an increase of the electrical conductivity for the overlimiting region of a current-voltage curve.

\subsection{Effect of $\mathrm{pH}$}

The effect of $\mathrm{pH}$ was evaluated by using $5.1 \mathrm{mmol} . \mathrm{L}^{-1} \mathrm{HEDP}$ solutions at $\mathrm{pH} 2$ and at $\mathrm{pH}$ 10. The chronopotentiometric curves obtained for the alkaline solution for three different current densities are shown in Figure 9.

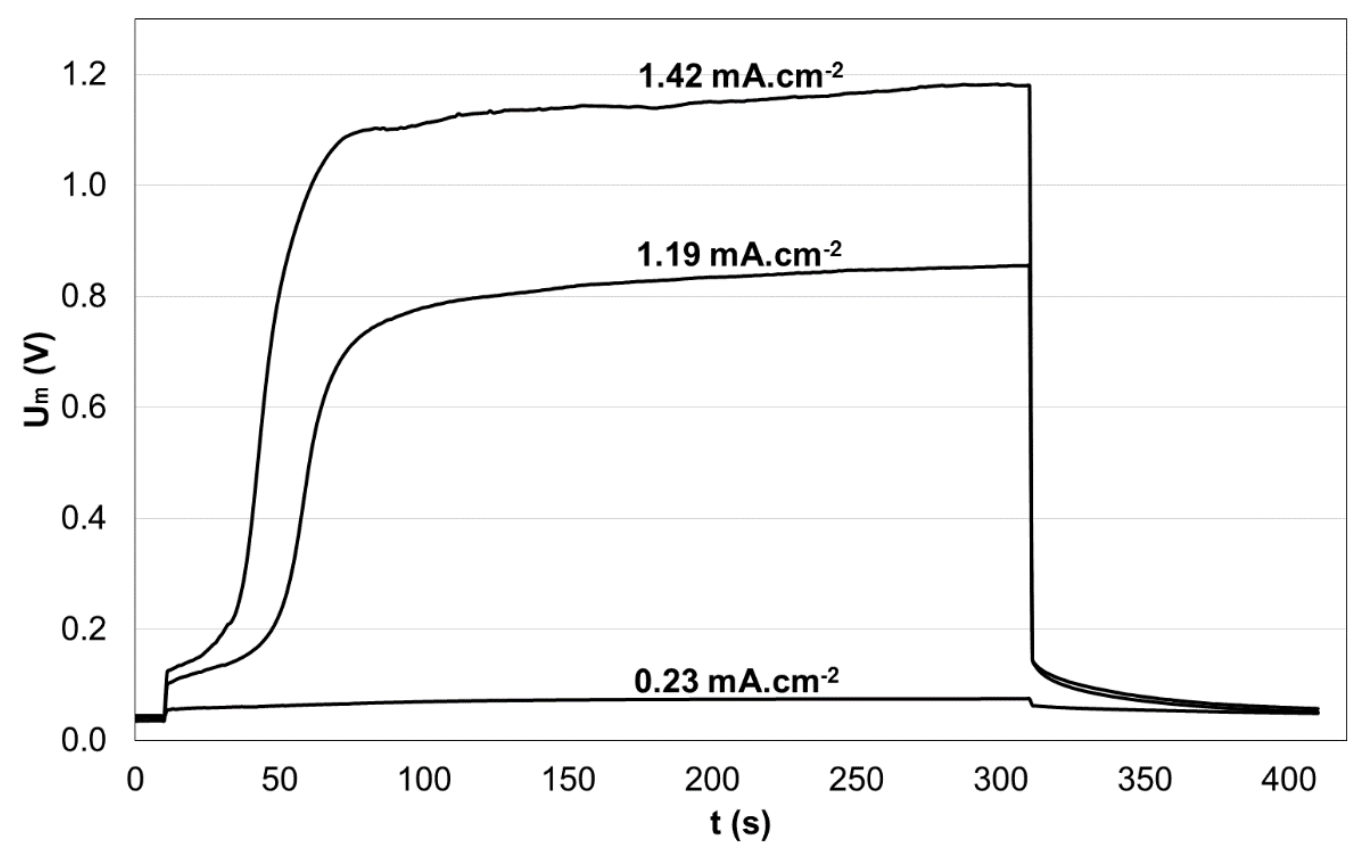

Figure 9. Chronopotentiometric curves obtained for $5.1 \mathrm{mmol}^{-L^{-1}} \mathrm{HEDP}$ solution at $\mathrm{pH} 10$.

The chronopotentiometric curves obtained for the alkaline HEDP solution presented typical characteristics of theoretical curves for monopolar ion exchange membranes. For current densities lower than the limiting current density, the curves showed a potential drop that can be attributed to the application of an electrical current between two electrodes. For higher current densities, the formation of a well-defined inflexion point was observed, related to the ion depletion at the diffusion boundary layer. 
For overlimiting regimes, the transition times decreased and the effects of overlimiting transfer mechanisms began to be observed.

Figure 10 presents the chronopotentiometric curves obtained for a HEDP solution with $\mathrm{pH} 2$.

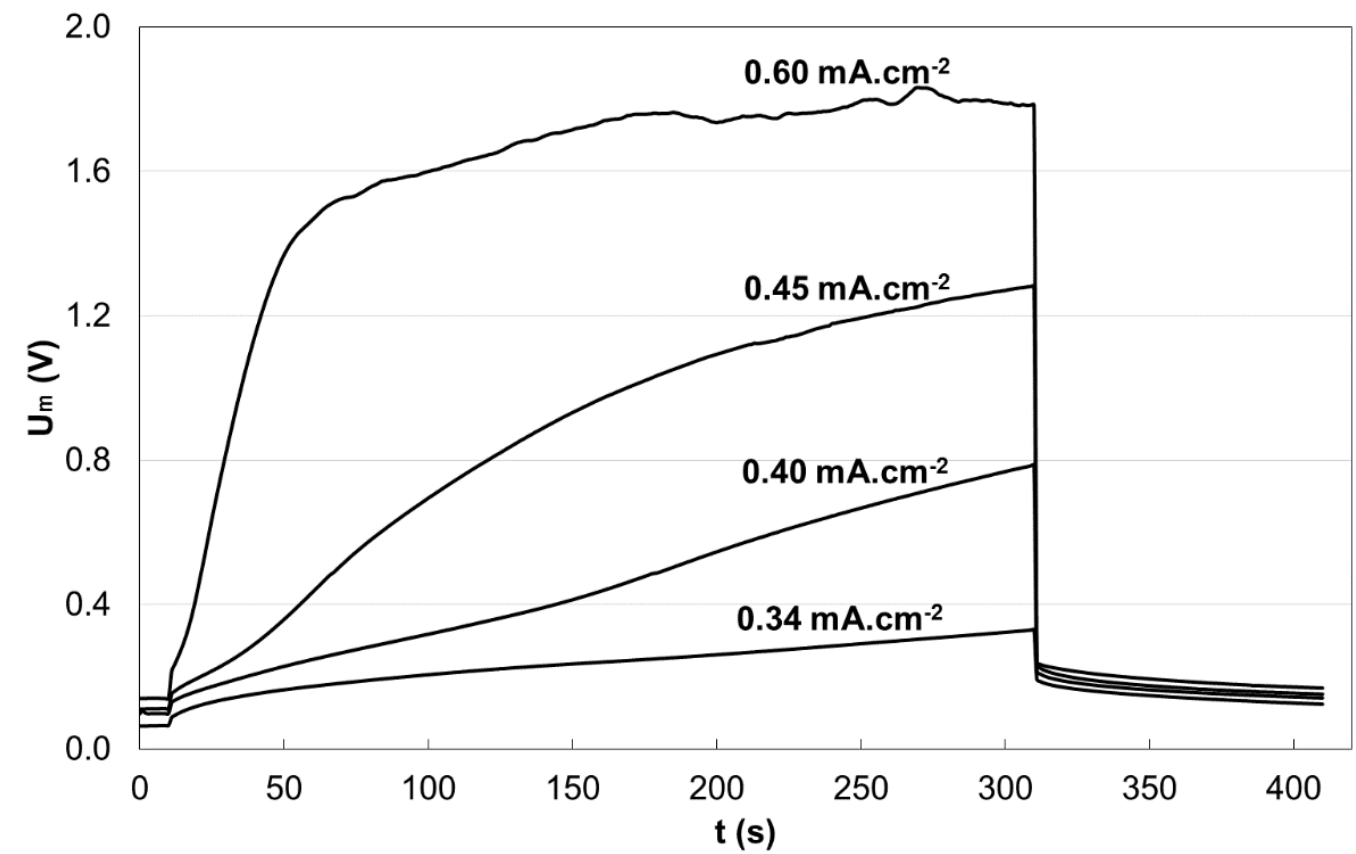

Figure 10. Chronopotentiometric curves obtained for HEDP $5.1 \mathrm{mmol}^{-\mathrm{L}^{-1}}$ with $\mathrm{pH} 2$.

At lower current densities $\left(0.34 \mathrm{~mA} . \mathrm{cm}^{-2}\right)$, the chronopotentiometric curve presented a similar behavior to the alkaline solution. Ions at the membrane/solution interface were not completely depleted and, thus, the curve did not show any inflexion point. However, for current densities between $0.40 \mathrm{~mA} . \mathrm{cm}^{-2}$ and $0.45 \mathrm{~mA} . \mathrm{cm}^{-2}$ which are higher than the limiting current density $\left(0.33 \mathrm{~mA} . \mathrm{cm}^{-2}\right.$, see Table 6$)$ the curves from Figure 10 did not seem to reach a stationary regime after the inflexion point, as observed for the alkaline solution. Instead, after ion depletion at the boundary layer, the potential difference increased continuously up to the interruption of the electrical current. For $0.60 \mathrm{~mA} . \mathrm{cm}^{-2}$, the curve presented instabilities after the inflexion point which may be attributed to the overlimiting transfer mechanisms.

The behavior of the chronopotentiometric curves for HEDP solution with $\mathrm{pH} 2$ may be discussed taking into account the ionic species from HEDP dissociation. For this evaluation, the equilibrium diagram for the HEDP solution at the initial state was analyzed (Figure 11). 


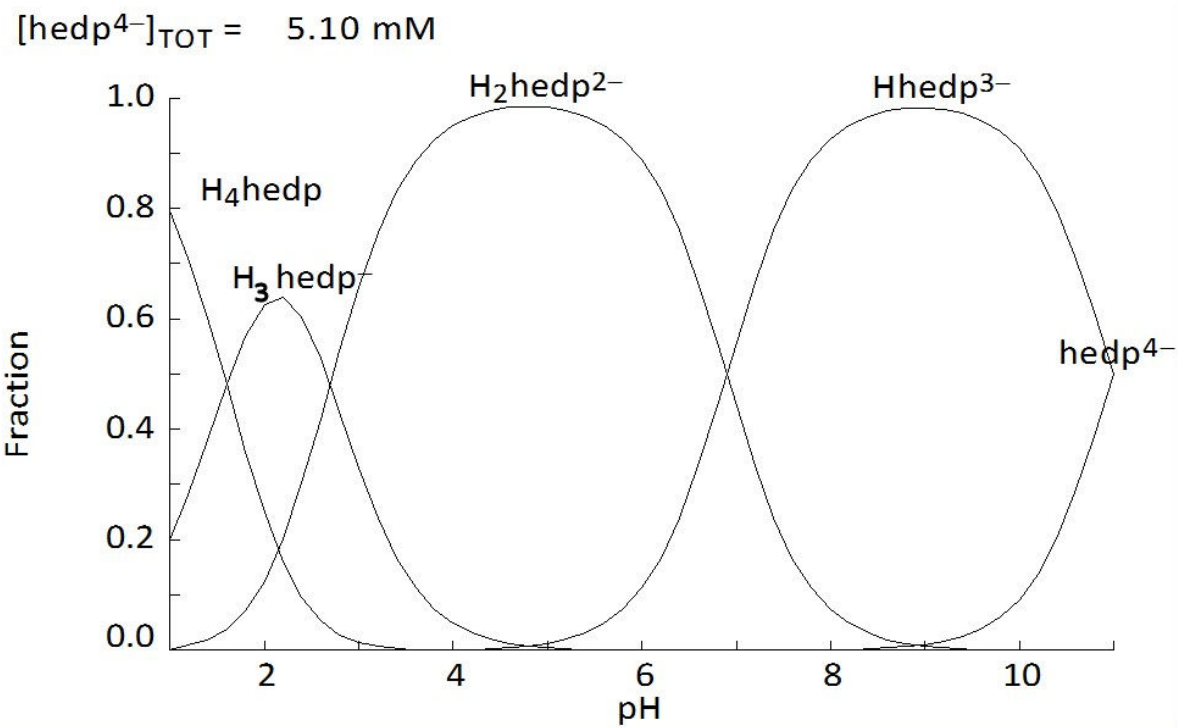

Figure 11. Equilibrium diagram of the HEDP solution. The equilibrium diagram was constructed with the aid of Hydra-Medusa software.

From Figure 11, it can be seen that, for $\mathrm{pH} 10$, the prevailing ionic species (about $90 \%$ ) is the $\mathrm{HHEDP}^{3-}$ anion. For $\mathrm{pH} 2$, about $60 \%$ of HEDP forms a monovalent species, $\mathrm{H}_{3} \mathrm{HEDP}^{-}$. At $\mathrm{pH} 10$, hydroxyl groups may be transferred towards the anodic side of the membrane faster than any other anion because of their greater mobility. The $\mathrm{H}^{+}$protons that remain in the boundary layer at the cathodic side are able to react with HEDP anions. For an alkaline solution, $\mathrm{H}^{+}$protons accumulated in the diffusion boundary layer favoring the formation of $\mathrm{H}_{2} \mathrm{HEDP}^{2-}$ according to Equations 1 and 2. However, for $\mathrm{pH} 2$, the most probable reaction would be the formation of a neutral species, $\mathrm{H}_{4} \mathrm{HEDP}$, following the reaction described by Equations 3 and 4. It is possible to observe in Figure 11 that, for $\mathrm{pH}$ below 1.6, HEDP is mostly uncharged. The formation of uncharged compounds can increase the electrical resistance during the application of the electrical current because they will not conduct ion current. The increase of the electrical resistance is observed in Figure 10 for $0.40 \mathrm{~mA} . \mathrm{cm}^{-2}$ and for $0.45 \mathrm{~mA} . \mathrm{cm}^{-2}$, represented by a constant increase of the membrane potential after the inflexion point.

The current-voltage curves for HEDP solutions for $\mathrm{pH} 2$ and for $\mathrm{pH} 10$ are presented in Figure 12. For $\mathrm{pH}$ 2, an increase in the electrical resistance in ohmic region $\left(R_{1}\right)$, a decrease in the limiting current density and an increase of the electrical resistance in overlimiting region and in plateau length were noticed. The main properties of the current-voltage curves are detailed in Table 6. 


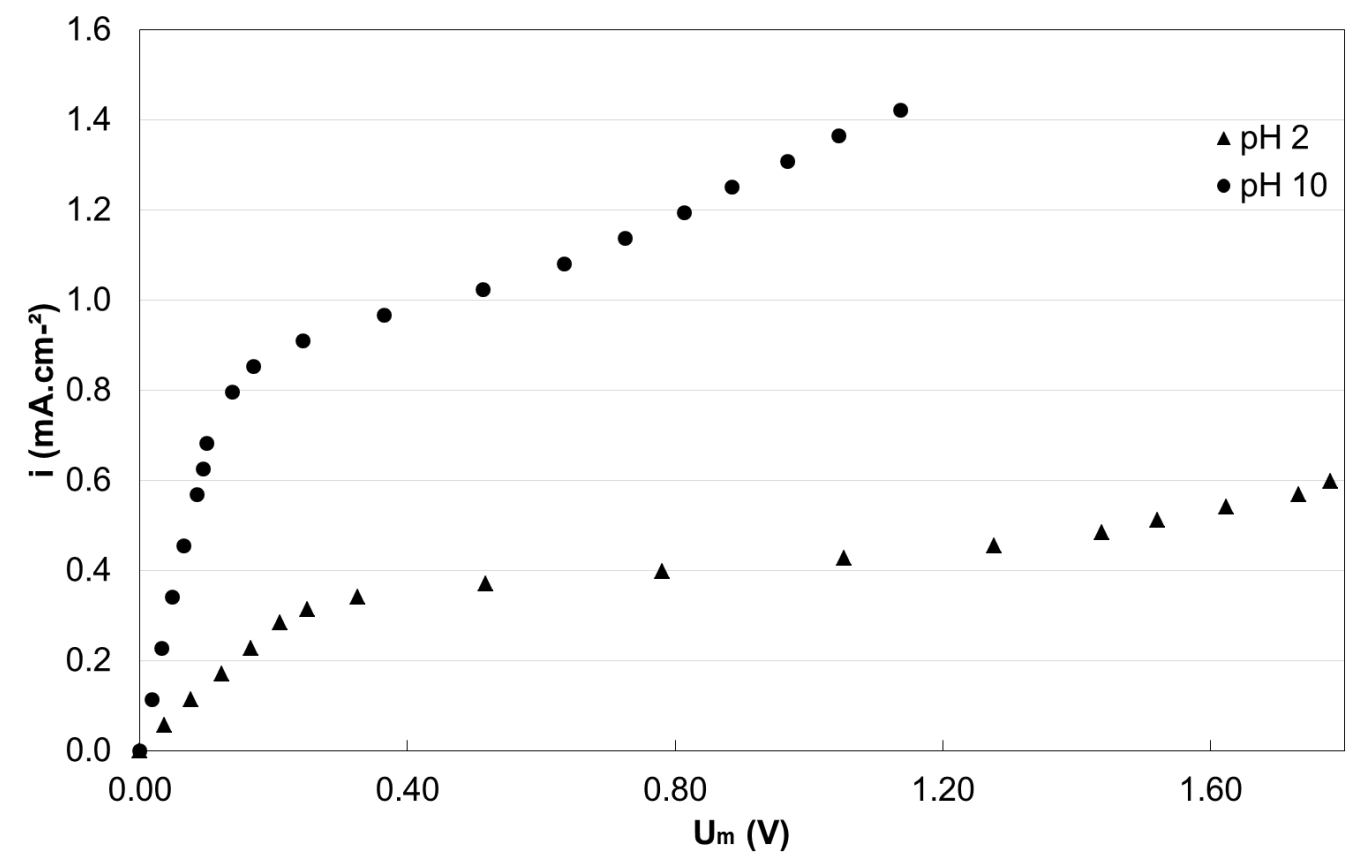

Figure 12. Current-voltage curves for $5.1 \mathrm{mmol}^{-1}$ HEDP solutions for $\mathrm{pH} 2$ and for $\mathrm{pH} 10$.

The ion transport rate across semipermeable membranes depends on the ion size, on the solvation degree and on the ion charge. Considering that both solutions have the same molar concentration, it is possible to relate the limiting current density and the HEDP charge using the Peer Equation $23[37,38]$.

$$
i_{l i m}=\frac{C_{0} \cdot F \cdot z_{j} \cdot D}{\delta\left(t_{j}^{m}-t_{j}^{S}\right)}
$$

In Equation 23, $C_{0}$ is the initial molar concentration, $F$ is the Faraday constant, $z_{j}$ is the charge of the ion $j, D$ is the diffusion coefficient, $\delta$ is the thickness of the diffusion boundary layer, $t^{\mathrm{m}}{ }_{\mathrm{j}}$ and $t^{s}$ are the transport numbers of $j$ species in the membrane and in the solution, respectively. The proportional relation between the ion charge $(z)$ and the limiting current density may be one of the causes of the greater limiting current density obtained for the HEDP solution for $\mathrm{pH} 10$. The lower electrical resistance presented by the alkaline solution and the higher limiting current density may also be explained by considering the higher concentration of hydroxyl groups, as shown in Table 6. The hydroxyl groups have greater mobility in anion exchange membranes [30]. On the other hand, the formation of $\mathrm{H}_{3} \mathrm{HEDP}^{-}$and $\mathrm{H}_{4} \mathrm{HEDP}$ can justify the changes in the transport properties for $\mathrm{pH} 2$, as discussed previously. 
Table 6. Main characteristics of $5.1 \mathrm{mmol} \cdot \mathrm{L}^{-1} \mathrm{HEDP}$ solutions.

\begin{tabular}{|c|c|c|}
\hline Composition & VI & VII \\
\hline $\operatorname{HEDP}\left(\mathrm{mmol} \cdot \mathrm{L}^{-1}\right)$ & 5.10 & 5.10 \\
\hline $\mathrm{K}^{+}\left(\mathrm{mmol} \cdot \mathrm{L}^{-1}\right)$ & 0.0 & 26.3 \\
\hline $\mathrm{pH}$ & 2.3 & 10.1 \\
\hline \multicolumn{3}{|c|}{ Current-voltage curve parameters } \\
\hline$l_{\text {lim }}\left(\mathrm{mA} \cdot \mathrm{cm}^{-2}\right)$ & 0.33 & 0.84 \\
\hline$R_{1}\left(\Omega \cdot \mathrm{cm}^{2}\right)$ & 761 & 144 \\
\hline$R_{3}\left(\Omega . \mathrm{cm}^{2}\right)$ & 3000 & 1450 \\
\hline Plateau length (V) & 0.50 & 1.14 \\
\hline \multicolumn{3}{|c|}{ 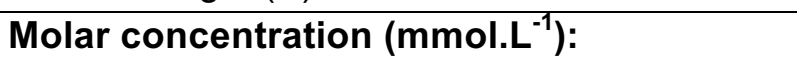 } \\
\hline $\mathrm{K}^{+}$ & 0.0 & 24.8 \\
\hline HHEDP ${ }^{3-}$ & $6.15 \times 10^{-5}$ & 4.61 \\
\hline $\mathrm{OH}^{-}$ & $2.82 \times 10^{-9}$ & 0.127 \\
\hline HEDP $^{4-}$ & $1.82 \times 10^{-13}$ & 0.611 \\
\hline $\mathrm{H}_{2} \mathrm{HEDP}^{2-}$ & 1.73 & $1.14 \times 10^{-3}$ \\
\hline $\mathrm{H}^{+}$ & 3.37 & $6.55 \times 10^{-8}$ \\
\hline $\mathrm{H}_{3} \mathrm{HEDP}^{-}$ & 2.94 & $\begin{array}{l}9.75 \times 10^{-} \\
11\end{array}$ \\
\hline $\mathrm{H}_{4} \mathrm{HEDP}$ & 0.58 & 0.0 \\
\hline \multicolumn{3}{|l|}{ Equivalent charge } \\
\hline$Q_{e q}^{+}$ & 3.37 & 24.8 \\
\hline$Q_{e q}^{-}$ & 6.41 & 16.4 \\
\hline$\Sigma\left(Q_{e q}\right)$ & 9.78 & 41.2 \\
\hline
\end{tabular}

Lastly, it is important to consider the anionic equivalent charge of both solutions. In Table 6, it is noted that the anionic equivalent charge of the alkaline solution is about 2.5 times higher than the acid solution. The relation between the equivalent charge and the main transport properties provided by CVC curves was discussed previously in Figure 7, in Figure 8 and in Table 5, and indicated that the same relation is suitable for the results of HEDP solutions.

\subsection{Effect of chloride addition}

In order to evaluate the effect of $\mathrm{Cl}^{-}$anions on the transport properties through HDX200 membrane, potassium chloride was added to the solutions HEDP: $\mathrm{Cu}^{2+}=7: 1$, as detailed in Table 7. The HEDP: $\mathrm{Cu}^{2+}$ ratio was maintained constant and the $\mathrm{pH}$ was adjusted to 10 by using a potassium hydroxide $50 \% \mathrm{~m} / \mathrm{v}$ solution.

Table 7. Composition of HEDP: $\mathrm{Cu}^{2+}=7: 1$ solutions after $\mathrm{KCl}$ addition in different concentrations.

ID Composition (mmol..-1 $\left.{ }^{-1}\right) \quad \mathrm{KCl}\left(\mathrm{mmol}^{-1} \mathrm{~L}^{-1}\right) \mathrm{pH}$




\begin{tabular}{cccc}
\hline VIII & $5.1 \mathrm{HEDP}+0.71 \mathrm{Cu}^{2+}$ & 0.94 & 10 \\
IX & $5.1 \mathrm{HEDP}+0.71 \mathrm{Cu}^{2+}$ & 5.10 & 10 \\
X & $5.1 \mathrm{HEDP}+0.71 \mathrm{Cu}^{2+}$ & 10.2 & 10 \\
XI & $0.71 \mathrm{HEDP}+0.10 \mathrm{Cu}^{2+}$ & 0.94 & 10 \\
\hline
\end{tabular}

The effect of chloride addition on the chronopotentiometric curves is shown in Figure 13.

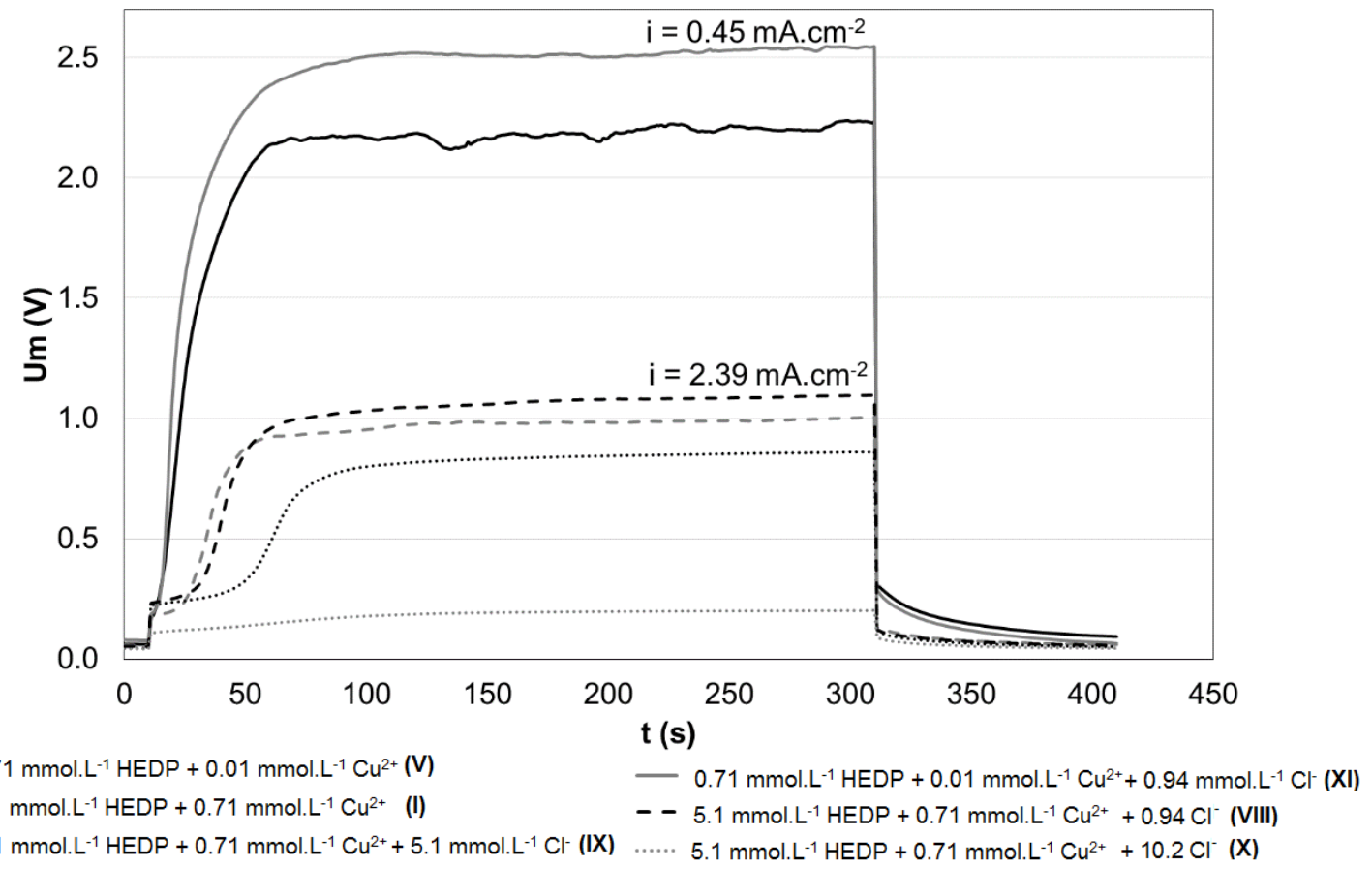

Figure 13. Chronopotentiometric curves obtained for solutions with different $\mathrm{Cl}^{-}$concentrations.

For $0.45 \mathrm{~mA} . \mathrm{cm}^{-2}$, the chloride addition in solutions with lower molar concentrations (solutions $\mathbf{V}$ and $\mathbf{X I}$ ) reduced and delayed the instabilities registered at overlimiting regimes. The instabilities are usually attributed to the change of transport mechanism from diffusion to an overlimiting mechanism that becomes important for higher current densities. When introducing chlorides which have a lower charge density, the potential fields between the heterogeneous membrane and the solution will be more uniformly dispersed, resulting in lower hydrodynamic instability when compared with species with higher charge density.

The chloride addition to the solutions with higher molar concentrations (solutions VIII, IX and $\mathbf{X}$ ) led to modifications in the appearance of the chronopotentiometric curves for $2.39 \mathrm{~mA} . \mathrm{cm}^{-2}$. The presence of chloride ions increased the equivalent charge and raised the limiting current density. It is observed in Figure 13 that, for $2.39 \mathrm{~mA} . \mathrm{cm}^{-2}$, the solution with higher amount of $\mathrm{Cl}^{-}$ions (solution $\mathbf{X}$ ) did not show any inflexion point (ohmic 
regime) while ion transport in the remaining solutions (I, VIII and IX) was being controlled by the diffusion mechanism.

The influence of chloride anions can be noticed by analyzing the CVC curves presented in

Figure 14.

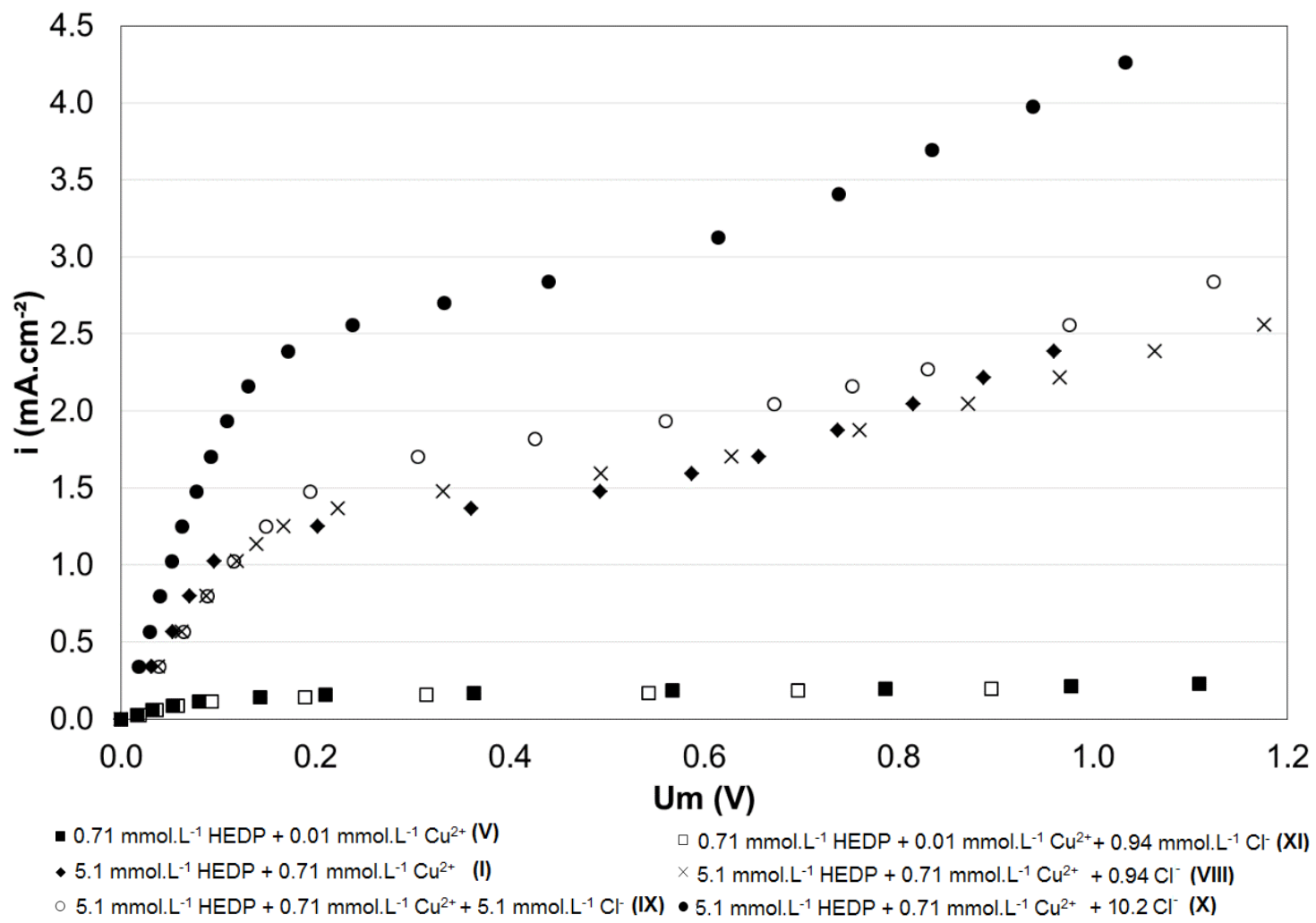

Figure 14. Current-voltage curves for HEDP: $\mathrm{Cu}^{2+}=7: 1$ solutions with addition of chloride in different concentrations.

The increase of the chloride concentration enhanced the limiting current density and reduced the electrical resistance both in the ohmic region and in overlimiting regimes. The $\mathrm{Cl}^{-}$concentration is higher than the $\mathrm{HHEDP}^{3-}$ concentration in solutions IX and $\mathbf{X}$, as it can be observed in

Table 8.

Table 8. Characteristics of solutions after chloride addition.

\begin{tabular}{lllll}
\hline Composition & VIII & IX & $\mathbf{X}$ & XI \\
\hline HEDP $\left(m m o l . L^{-1}\right)$ & 5.10 & 5.10 & 5.10 & 0.71 \\
$\mathrm{Cu}^{2+}\left(\mathrm{mmol} . \mathrm{L}^{-1}\right)$ & 0.71 & 0.71 & 0.71 & 0.10
\end{tabular}




\begin{tabular}{|c|c|c|c|c|}
\hline $\mathrm{K}^{+}\left(\mathrm{mmol} . \mathrm{L}^{-1}\right)$ & 29.0 & 34.0 & 37.8 & 4.96 \\
\hline $\mathrm{Cl}^{-}\left(\mathrm{mmol} \cdot \mathrm{L}^{-1}\right)$ & 0.94 & 5.10 & 10.20 & 0.94 \\
\hline $\mathrm{pH}$ & 10.07 & 10.19 & 9.97 & 9.98 \\
\hline \multicolumn{5}{|c|}{ CVC properties } \\
\hline$l_{\lim }\left(\mathrm{mA} \cdot \mathrm{cm}^{-2}\right)$ & 1.32 & 1.59 & 2.31 & 0.14 \\
\hline$R_{1}\left(\Omega . \mathrm{cm}^{2}\right)$ & 127.0 & 121.0 & 57.2 & 686.0 \\
\hline$R_{3}\left(\Omega . \mathrm{cm}^{2}\right)$ & 610.0 & 546.0 & 350.0 & 4869.0 \\
\hline Plateau (V) & 0.54 & 0.53 & 0.59 & 1.46 \\
\hline \multicolumn{5}{|c|}{ 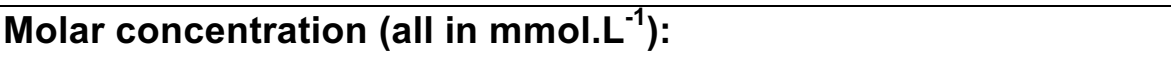 } \\
\hline $\mathrm{K}^{+}$ & 28.91 & 34.04 & 37.50 & 4.95 \\
\hline $\mathrm{HHEDP}^{3-}$ & 3.89 & 3.84 & 3.99 & 0.57 \\
\hline $\mathrm{Cl}^{-}$ & 0.94 & 5.04 & 10.12 & 0.96 \\
\hline$[\mathrm{CuHEDP}]^{2-}$ & 0.71 & 0.71 & 0.71 & 0.10 \\
\hline $\mathrm{SO}_{4}^{2-}$ & 0.59 & 0.57 & 0.56 & 0.10 \\
\hline $\mathrm{HEDP}^{4-}$ & 0.45 & 0.52 & 0.37 & 0.05 \\
\hline $\mathrm{KSO}_{4}^{-}$ & 0.12 & 0.14 & 0.15 & 0.00 \\
\hline $\mathrm{OH}^{-}$ & 0.12 & 0.13 & 0.09 & 0.08 \\
\hline \multicolumn{5}{|c|}{ Equivalent charge } \\
\hline$Q_{\text {eq }}^{+}$ & 28.91 & 34.04 & 37.50 & 4.96 \\
\hline$Q_{e q}^{-}$ & 17.27 & 21.46 & 26.37 & 3.34 \\
\hline$\Sigma\left(Q_{e q}\right)$ & 46.18 & 55.50 & 63.86 & 8.30 \\
\hline
\end{tabular}

In solutions IX and $\mathbf{X}$, the equivalent charge is more influenced by the presence of $\mathrm{Cl}^{-}$anions which promoted the changes in the CVC curves. From

Table 8, it is noted that chloride addition promoted a slight increase in the plateau length which was previously discussed based on the relation between the Stokes radius and the activation of electroconvection.

\section{CONCLUSIONS}

The present study proposed a detailed investigation on the transport properties of copper chelates across an anion-exchange membrane in etidronic acid solutions using chronopotentiometry. The presence of chelate anions increased the electrical resistance and reduced the limiting current density of the evaluated systems. Under specific conditions $\left(i \approx i_{\text {lim }}\right.$ and HEDP: $\left.\mathrm{Cu}^{2+}=4\right)$, it was possible to distinguish the transition times 
assigned to free HEDP and to copper chelates. The migration of chelates was slower than free HEDP, probably because of their lower mobility in the membrane.

The transport properties were also influenced by the anionic equivalent charge of the studied solutions. Solutions having the greatest equivalent charge presented higher limiting current density and smaller electrical resistance. The exception was the solution having HEDP: $\mathrm{Cu}^{2+}=1$. In that case, the effect of the high amount of chelates was more relevant than the anionic equivalent charge. It was found a relation between the anionic equivalent charge and the plateau length of the current-voltage curves. The higher equivalent charges were able to activate the overlimiting mechanisms faster and, consequently, the corresponding current-voltage curves presented a shorter plateau. The activation of overlimiting mechanisms was also found to be faster in the presence of anions with greater Stokes radius.

In acid HEDP medium ( $\mathrm{pH} \approx 2$ ), the overlimiting regimes may favor the formation of non-charged species and difficult the acid extraction. On the other hand, the chloride addition raised the limiting current density and the electrical conductivity. The presence of chloride anions delayed the change of mechanism from diffusion to overlimiting regimes. This behavior could be noted in the CVC curves, because of longer plateau lengths, and in the chronopotentiograms, because of the less evident instabilities attributed to overlimiting regimes.

\section{ACKNOWLEDGEMENTS}

Authors would like to thank the Institute for Technological Research (IPT), the Institute for Technological Research Foundation (FIPT), to the São Paulo Research Foundation (Fapesp - processes 2012/51871-9 and 2014/13351-9) and the National Council for Scientific and Technological Development.

\section{REFERENCES}

[1] E. Volodina, N. Pismenskaya, V. Nikonenko, C. Larchet, G. Pourcelly, lon transfer across ion-exchange membranes with homogeneous and heterogeneous surfaces, J. Colloid Interface Sci. $285 \quad$ (2005) 247-258. doi:10.1016/j.jcis.2004.11.017.

[2] J.-H. Choi, S.-H. Kim, S.-H. Moon, Heterogeneity of Ion-Exchange Membranes: The Effects of Membrane Heterogeneity on Transport Properties., J. Colloid Interface Sci. 241 (2001) 120-126. doi:10.1006/jcis.2001.7710.

[3] L. Marder, E.M. Ortega, V. Pérez-herranz, A. Moura, J. Zoppas, 
Chronopotentiometric study on the effect of boric acid in the nickel transport properties through a cation-exchange membrane, Desalination. 249 (2009) 348352. doi:10.1016/j.desal.2009.06.040.

[4] I. Herraiz-Cardona, E. Ortega, V. Pérez-Herranz, Evaluation of the Zn $2+$ transport properties through a cation-exchange membrane by chronopotentiometry, J. Colloid Interface Sci. 341 (2010) 380-385. doi:10.1016/j.jcis.2009.09.053.

[5] M.C. Martí-Calatayud, M. García-Gabaldón, V. Pérez-Herranz, E. Ortega, Determination of transport properties of $\mathrm{Ni}$ ( II ) through a Nafion cation-exchange membrane in chromic acid solutions, J. Memb. Sci. 379 (2011) 449-458. doi:10.1016/j.memsci.2011.06.014.

[6] V. V. Nikonenko, A. V. Kovalenko, M.K. Urtenov, N.D. Pismenskaya, J. Han, P. Sistat, G. Pourcelly, Desalination at overlimiting currents: State-of-the-art and perspectives, Desalination. 342 (2014) 85-106. doi:10.1016/j.desal.2014.01.008.

[7] S. V. Shishkina, E.S. Pechenkina, a. V. Dyukov, Transport properties of anionexchange membranes: Effect of the formation of complexes, Russ. J. Electrochem. 42 (2006) 1310-1318. doi:10.1134/S102319350612007X.

[8] F. Aouad, A. Lindheimer, M. Chaouki, C. Gavach, Loss of permselectivity of anion exchange membranes in contact with zinc chloride complexes, Desalination. 121 (1999) 13-22. http://linkinghub.elsevier.com/retrieve/pii/S001191649900003X.

[9] M. a S. Rodrigues, C. Korzenovski, E. Gondran, a. M. Bernardes, J.Z. Ferreira, Evaluation of changes on ion-selective membranes in contact with zinc-cyanide complexes, J. Memb. Sci. $279 \quad$ (2006) 140-147. doi:10.1016/j.memsci.2005.11.045.

[10] M.A.S. Rodrigues, F.D.R. Amado, M.R. Bischoff, C.A. Ferreira, A.M. Bernardes, J.Z. Ferreira, Transport of zinc complexes through an anion exchange membrane, Desalination. 227 (2008) 241-252. doi:10.1016/j.desal.2007.07.018.

[11] L. Marder, A.M. Bernardes, J. Zoppas Ferreira, Cadmium electroplating wastewater treatment using a laboratory-scale electrodialysis system, Sep. Purif. Technol. 37 (2004) 247-255. doi:10.1016/j.seppur.2003.10.011.

[12] F.G. Wilhelm, N.F. a. van der Vegt, M. Wessling, H. Strathmann, Chronopotentiometry for the advanced current-voltage characterisation of bipolar 
membranes, J. Electroanal. Chem. 502 (2001) 152-166. doi:10.1016/S00220728(01)00348-5.

[13] N. Pismenskaia, P. Sistat, P. Huguet, V. Nikonenko, G. Pourcelly, Chronopotentiometry applied to the study of ion transfer through anion exchange membranes, J. Memb. Sci. 228 (2004) 65-76. doi:10.1016/j.memsci.2003.09.012.

[14] J.J. Krol, M. Wessling, H. Strathmann, Chronopotentiometry and overlimiting ion transport through monopolar ion exchange membranes, J. Memb. Sci. 162 (1999) 155-164. doi:10.1016/S0376-7388(99)00134-9.

[15] S.A. Mareev, D.Y. Butylskii, N.D. Pismenskaya, V. V. Nikonenko, Chronopotentiometry of ion-exchange membranes in the overlimiting current range. Transition time for a finite-length diffusion layer: Modeling and experiment, J. Memb. Sci. 500 (2016) 171-179. doi:10.1016/j.memsci.2015.11.026.

[16] L. Marder, E.M. Ortega Navarro, V. Pérez-Herranz, A.M. Bernardes, J.Z. Ferreira, Evaluation of transition metals transport properties through a cation-exchange membrane by chronopotentiometry, J. Memb. Sci. 284 (2006) 267-275. doi:10.1016/j.memsci.2006.07.039.

[17] T.P. Knepper, Synthetic chelating agents and compounds exhibiting complexing properties in the aquatic environment, TrAC - Trends Anal. Chem. 22 (2003) 708724. doi:10.1016/S0165-9936(03)01008-2.

[18] Z.-L. Wang, Y.-X. Yang, J.-B. Zhang, H. Zhu, Y.-R. Chen, A study on electroplating of zinc nickel alloy with HEDP plating bath, Russ. J. Electrochem. 42 (2006) 2226. doi:10.1134/S1023193506010046.

[19] C.V. Pecequilo, Z. Panossian, Study of copper electrodeposition mechanism from a strike alkaline bath prepared with 1-hydroxyethane-1,1-diphosphonic acid through cyclic voltammetry technique, Electrochim. Acta. 55 (2010) 3870-3875. doi:10.1016/j.electacta.2010.01.113.

[20] W. Deqing, S. Ziyuan, K. Tangshan, Composite plating of hard chromium on aluminum substrate, Surf. Coatings Technol. 191 (2005) 324-329. doi:10.1016/j.surfcoat.2004.03.049.

[21] V. Deluchat, Divalent cations speciation with three phosphonate ligands in the $\mathrm{pH}$ range of natural waters, Talanta. 44 (1997) 897-907. doi:10.1016/S00399140(96)02136-4. 
[22] V.S. Sergienko, Structural Chemistry of 1-Hydroxyethylidenediphosphonic Acid Complexes, Russ. J. Coord. Chem. 27 (2001) 681-710.

[23] T. Scarazzato, D.C. Buzzi, A.M. Bernardes, D.C. Romano Espinosa, Treatment of wastewaters from cyanide-free plating process by electrodialysis, J. Clean. Prod. (2014) 1-10. doi:10.1016/j.jclepro.2014.12.046.

[24] M.C. Martí-calatayud, D.C. Buzzi, M. García-gabaldón, A.M. Bernardes, J.A.S. Tenório, V. Pérez-Herranz, lon transport through homogeneous and heterogeneous ion-exchange membranes in single salt and multicomponent electrolyte solutions, J. Memb. Sci. $466 \quad$ (2014) 45-57. doi:10.1016/j.memsci.2014.04.033.

[25] M.-S. Kang, Y.-J. Choi, H.-J. Lee, S.-H. Moon, Effects of inorganic substances on water splitting in ion-exchange membranes, J. Colloid Interface Sci. 273 (2004) 523-532. doi:10.1016/j.jcis.2004.01.050.

[26] S. Lacour, V. Deluchat, J.C. Bollinger, Bernard Serpaud, Complexation of trivalent cations ( $\mathrm{Al}(\mathrm{III}), \mathrm{Cr}(\mathrm{III}), \mathrm{Fe}(\mathrm{III}))$ with two phosphonic acids in the $\mathrm{pH}$ range of fresh waters, Talanta. 46 (1998) 999-1009. doi:10.1016/S0039-9140(97)00369-X.

[27] K. Fischer, Distribution and elimination of HEDP in aquatic test systems, Water Res. 27 (1993) 485-493. doi:10.1016/0043-1354(93)90049-N.

[28] D. Kołodyńska, Cu ( II ), Zn ( II ), Ni ( II ), and Cd ( II ) Complexes with HEDP Removal from Industrial Effluents on Different Ion Exchangers, Ind. Eng. Chem. Res. 49 (2010) 2388-2400.

[29] J.M. Zook, S. Bodor, R.E. Gyurcsányi, E. Lindner, Interpretation of chronopotentiometric transients of ion-selective membranes with two transition times, J. Electroanal. Chem. $638 \quad$ (2010) 254-261. doi:10.1016/j.jelechem.2009.11.007.

[30] N. Pismenskaya, V. Nikonenko, B. Auclair, G. Pourcelly, Transport of weakelectrolyte anions through anion exchange membranes Current - voltage characteristics, J. Memb. Sci. 189 (2001) 129-140.

[31] M. García-Gabaldón, V. Pérez-Herranz, E. Ortega, Evaluation of two ionexchange membranes for the transport of tin in the presence of hydrochloric acid, J. Memb. Sci. 371 (2011) 65-74. doi:10.1016/j.memsci.2011.01.015. 
[32] P. Długołęcki, B. Anet, S.J. Metz, K. Nijmeijer, M. Wessling, Transport limitations in ion exchange membranes at low salt concentrations, J. Memb. Sci. 346 (2010) 163-171. doi:10.1016/j.memsci.2009.09.033.

[33] S. Sang, Q. Wu, K. Huang, A discussion on ion conductivity at cation exchange membrane/solution interface, Colloids Surfaces A Physicochem. Eng. Asp. 320 (2008) 43-48. doi:10.1016/j.colsurfa.2008.01.010.

[34] M.C. Martí-Calatayud, M. García-Gabaldón, V. Pérez-Herranz, Study of the effects of the applied current regime and the concentration of chromic acid on the transport of Ni 2 + ions through Nafion 117 membranes, J. Memb. Sci. 392-393 (2012) 137-149. doi:10.1016/j.memsci.2011.12.012.

[35] E. Belova, G. Lopatkova, N. Pismenskaya, V. Nikonenko, C. Larchet, Role of water splitting in development of electroconvection in ion-exchange membrane systems, Desalination. 199 (2006) 59-61. doi:10.1016/j.desal.2006.03.142.

[36] J.-H. Choi, H.-J. Lee, S.-H. Moon, Effects of Electrolytes on the Transport Phenomena in a Cation-Exchange Membrane., J. Colloid Interface Sci. 238 (2001) 188-195. doi:10.1006/jcis.2001.7510.

[37] A. Chapotot, G. Pourcelly, C. Gavach, Transport competition between monovalent and divalent cations through cation-exchange membranes. Exchange isotherms and kinetic concepts, J. Memb. Sci. 96 (1994) 167-181. doi:10.1016/03767388(94)00107-3.

[38] M.L. Vásquez-Garzón, G. Bonotto, L. Marder, J.Z. Ferreira, A.M. Bernardes, Transport properties of tartrate ions through an anion-exchange membrane, Desalination. 263 (2010) 118-121. doi:10.1016/j.desal.2010.06.047. 